El espacio público en conflicto: Coordenadas conceptuales Y TENSIONES IDEOLÓGICAS

\title{
Public Space in Conflict: Conceptual Coordinates and Ideological Tensions
}

\section{Andrés Di Masso Tarditti ; Héctor Berroeta**;} Tomeu Vidal Moranta*

* Universitat de Barcelona; * Universidad de Valparaiso; adimasso@ub.edu

Historia editorial
Recibido: $16-10-2015$
Aceptado: $14-07-2017$

Palabras clave

Espacio público

Conflicto

Ideología

Derecho a la ciudad Resumen

En este artículo aportamos herramientas conceptuales y argumentativas para pensar y problematizar la noción de "espacio público". Comenzamos esbozando los principales marcos discursivos desde los que se define "el espacio público" como objeto de reflexión en los estudios urbanos. Asumiendo la crítica neo-marxista al ideal normativo del espacio público como estándar ideológico mistificador de desigualdades sociales estructurales, subrayamos la inadecuación teórica y política resultante de ignorar la naturaleza contestada del espacio público como ámbito de territorialización de procesos y luchas sociales más amplios. Desarrollamos esta concepción crítica del espacio público como un lugar en el que se articula materialmente una disputa de orden ideológico en torno a la definición de los contornos de la publicidad legítima y la naturalización clasista del derecho a censurar y a excluir. Finalmente, señalamos algunas de las modalidades de conflicto urbano más prominentes que apuntalan esta visión desestabilizadora del espacio público normativo.

\section{Abstract}

Keywords

Public Space

Conflict

Ideology

Right to the City

In this article we provide conceptual and argumentative tools to think and to problematize the notion of "public space". We start outlining the main discursive frames that are usually used to define "the public space" as a research object in urban studies. Drawing on the neo-Marxist critique to the normative ideal of public space as an ideological standard that mystifies structural social inequalities, we underline the theoretical and political inadequacy that derives from ignoring the contested nature of public space as an arena for the territorialisation of broader social struggles. We develop this critical view of public space as a site in which an ideological dispute takes place, revolving around the definition of the boundaries of the legitimate publics and the classist naturalization of the right to exclude. Finally, we outline some of the most common modalities of urban conflict that underpin this destabilizing view of the normative public space.

Di Masso, Andrés; Berroeta, Héctor \& Vidal, Tomeu (2017). El espacio público en conflicto: Coordenadas conceptuales y tensiones ideológicas. Athenea Digital, 17(3), 53-92. https://doi.org/10.5565/rev/athenea.1725

\section{Introducción}

En el contexto de los cambios urbanos propios de la ciudad post-fordista (ver Smith, 2005; Soja, 1989), una creencia tácita parece haberse consolidado en el cruce entre los discursos de académicos, políticos, medios de comunicación, tecnócratas del márqueting urbano y movimientos sociales, según la cual los espacios públicos son un componente crucial de la vida en común y de la justicia social. A día de hoy, ignorar el espacio público en el marco de cualquier debate sobre el devenir urbano equivale a ser insensible a los derechos, necesidades y deseos elementales de las personas que viven en 
la ciudad. Complementariamente, la acción decidida sobre el espacio público parece ser una condición ineludible tanto para contribuir a restaurar la desgastada legitimidad de las instituciones políticas en sus arrebatos desesperados por gobernar lo que queda de "lo común", como para articular una propuesta política contundente y verdaderamente antagonista contra el actual ciclo de desposesión vital propia del capitalismo neoliberal, visto desde el ángulo de los movimientos urbanos autónomos (Castells, 1986).

Exceptuando algunas aportaciones indispensables que problematizan esta convicción paradójicamente común a las más profundas discrepancias ideológicas (Delgado, 2011; Mitchell, 2003), parece razonable afirmar que los discursos y prácticas actuales sobre lo urbano incluyen un elevado grado de consenso en torno a la idea de que el espacio público es un componente clave de la vida social en la ciudad. Por supuesto, el sentido ideológico que adquiere "el espacio público" varía enormemente, dependiendo siempre del efecto concreto que implican y producen sus acciones y discursos asociados sobre una red socialmente organizada de relaciones de hegemonía (Žižek, 1994), materializadas en usos, formas y regulaciones específicas del espacio urbano. Así, en paralelo al consenso en torno a su relevancia social, el significado político del espacio público se refracta en sentidos muy dispares si se atiende al impacto que tienen sus discursos y prácticas sobre las condiciones geográficas del orden social.

Con este planteamiento como punto de partida, en este artículo proponemos una síntesis crítica de las interpretaciones habituales e inhabituales sobre el espacio público existentes, a grandes rasgos, en el imaginario urbano actual. Para ello, exponemos en primer lugar los principales marcos discursivos en torno a los cuales se organiza el pensamiento académico contemporáneo sobre el espacio público, más o menos afines al sentido común y a las aproximaciones al espacio público de signo mediático o divulgativo. A continuación, señalamos y discutimos las principales tensiones ideológicas inherentes a la naturaleza "pública" del espacio público y que son comunes al grueso de sus definiciones al uso, independientemente de su encuadre discursivo. Por último, focalizamos sobre las variantes y características del conflicto en el espacio público entendido como un ámbito de territorialización de procesos y luchas sociales más amplios. El objetivo último del artículo es aportar herramientas conceptuales y argumentativas que permitan precisar, ensanchar y problematizar las comprensiones normalizadas sobre el espacio público en el marco de los procesos contemporáneos de captura neoliberal del espacio común de la ciudad. 


\section{Marcos discursivos sobre el espacio público}

Como todo tópico que irrumpe en el debate social, el espacio público aparece como objeto de interés en el mundo político, mediático y académico, así como en la conversación cotidiana, en el seno de un entramado de políticas de representación variables y contestadas. Por "política de representación" entenderemos una forma culturalmente estabilizada de construir y regular el significado de un objeto particular. Más allá de las representaciones sociales, las políticas de representación implican la movilización simbólica y material de mecanismos y fuerzas sociales articulados en torno al poder de nombrar dicho objeto, de definir los contornos normativos de su significado y de legitimar las acciones materiales realizadas en su nombre (Barker y Galasinski, 2001). Proponemos aquí tres grandes perspectivas o tendencias discursivas que se sitúan en la base de las políticas de representación del espacio público, a partir de una revisión de la literatura interdisciplinar sobre el tema. Estas tres tesis plantean tres visiones distintas sobre el pasado y el futuro de los espacios públicos en relación a los cambios contemporáneos en la vida pública, y sus presuposiciones y argumentos muestran sensibilidades analíticas dispares, con consecuencias políticas e ideológicas notablemente diferentes. Llamaremos a estas tres perspectivas la tesis optimista, la tesis terminal y la tesis conflictivista. Esta distinción pretende ser útil para reflexionar sobre los diferentes esquemas de premisas que fundamentan lo pensable y lo deseable, lo normativo y lo censurable, en relación al espacio público.

\section{La tesis optimista}

Esta perspectiva recoge una serie de aproximaciones que parten de una paradoja y de una crítica a otros enfoques sobre el espacio público. En cuanto a la paradoja, se considera que existe actualmente una desaparición progresiva de formas tradicionales de vida pública en paralelo a un sorprendente resurgimiento del espacio público (Brill, 1989; Carr, Francis, Rivlin y Stone, 1992). El argumento principal de esta perspectiva es que, si bien el espacio público padece el acoso de los vectores de privatización y mercantilización de la vida pública, ésta no ha desaparecido (en general) sino que ha variado en cuanto a sus formas, localizaciones y funciones. Si se asume que el espacio público debe albergar y fomentar el desarrollo de la vida pública, en la medida en que la vida pública cumple funciones diferentes, los espacios públicos deben adaptarse a estas nuevas funciones.

¿Cuáles son las nuevas formas, localizaciones y funciones de la vida pública según esta perspectiva? Autores como Michael Brill (1989) mencionan los periódicos, Internet, la radio, las representaciones teatrales en la calle, las telecomunicaciones, los cen- 
tros comerciales, los recintos feriales, los parques temáticos, etc. Estas formas dominantes de vida pública son distintas de las formas tradicionales porque éstas últimas se orientaban exclusivamente a proporcionar oportunidades de descanso a las personas tras jornadas laborales agotadoras y a compensar las condiciones de hacinamiento doméstico, además de funcionar de forma determinante como ámbitos de control social informal, de encuentro y de apoyo social primario. La vida pública de hoy cumpliría otras funciones más ligadas a la elección, muchas veces individual, de espacios públicos para experimentar placer sensorial, hacer ejercicio, entretenerse, descubrir emociones nuevas, consumir, aislarse, etc. Naturalmente, funciones clásicas de la vida pública en el espacio público se mantendrían, como la representación pública del disentimiento político o la búsqueda de espacios para el ocio con otras personas, el descanso y la relajación tras la jornada laboral.

La crítica central que formula la tesis optimista se relaciona con la extendida preocupación actual por una supuesta pérdida dramática de espacio público. La narrativa de la pérdida contemporánea de espacio público está basada en una visión idealizada y romantizada del espacio público del pasado, como si éste en una época hubiera representado el epítome del intercambio social directo, verbal, cálido, cara a cara, caracterizado por la mezcla armónica y pacífica en la diversidad y por una actividad política bullente y permanente. Este ideal normativo del espacio público no habría existido jamás, según la tesis optimista, que recomienda hacer una mirada más justa al pasado del espacio público (menos ideal de lo que se supone, por haber albergado históricamente también formas de pobreza y desigualdad social, como hoy) y propone afinar más la mirada hacia las nuevas modalidades, ubicaciones y funciones de los espacios públicos contemporáneos.

No debería resultar sorprendente, por tanto, que la defensa de un resurgimiento de la vida pública complementaria a un declive de sus viejas formas plantee la posibilidad de trabajar para descubrir y modelar nuevos espacios públicos capaces de servir a las nuevas formas y funciones de la vida pública. Dentro de esta tesis optimista se ubica la mayoría de las propuestas de criterios óptimos de intervención sobre el espacio público que supuestamente garantizan su buen funcionamiento social: derecho de presencia, uso y acción, apropiación, modificación y disposición (Lynch, 1981); posibilidades de comer, sentarse, relajarse, mirar y disfrutar (Whyte, 1980); fomento de una máxima diversidad social; accesibilidad; participación directa en su creación, uso y gestión; control por parte del propio usuario; calidad ecológica; y posibilidad de descubrir nuevas sensaciones (Abu-Ghazzeh, 1996; Appleyard, 1981; Francis, 1989); etc. 
Curiosamente, no obstante, la perspectiva optimista sobre el espacio público muestra una faceta pesimista, en ocasiones incluso catastrofista ${ }^{1}$. Esta faceta viene representada por los discursos del riesgo, la prevención y la punición ante un supuesto incremento alarmante (siempre estacionado en su crecimiento) de la inseguridad y de los comportamientos "incívicos" (indecentes, degradantes, inmorales, etc.) en calles y otros espacios públicos de la ciudad. En este marco interpretativo, el espacio público es retratado como un territorio en permanente riesgo de anomia y "pánico moral" (Cohen, 2002) atribuible a grupos o colectivos sociales cuyo uso "impropio" del espacio atenta contra un postulado "bien común". Si bien el discurso alarmista de la inseguridad, el incivismo y la anomia urbana contradice el espíritu propio de la tesis optimista, su despliegue retórico alimenta el desiderátum normativo de paz, consenso y armonía propio de esa perspectiva, cuyo horizonte político traza una convivencia social funcionalmente adaptada a la celebración a-problemática de un espacio público donde, en el fondo, todo va bien.

\section{La tesis terminal}

Esta segunda perspectiva proclama un inminente fin del espacio público en las ciudades contemporáneas, al menos en EEUU y buena parte de Centro y Suramérica. La tesis terminal se sostiene sobre ese pasado idealizado y romantizado criticado por la tesis optimista (si bien con ciertos matices ${ }^{2}$ ). Dentro de esta perspectiva encontramos la aportación clásica de Richard Sennett (1974), quien anunció y denunció explícitamente la "muerte de los espacios públicos". Esta defunción se habría producido por el predominio cultural de la intimidad y la privacidad en las relaciones sociales, llevando a los individuos a concebir el dominio público como carente de sentido. Sennett señala una

\footnotetext{
Queremos agradecer, sobre este punto en particular, las respectivas aportaciones a la discusión por parte de Verónica Urzúa, Pep Vivas, Mamen Peñaranda, Félix Pérez, Simoes de Almeida y Ramón Ribera-Fumaz en el marco del simposio Saturación y desaparición del espacio público: nuevas reflexiones para su "recuperación" (XI Congreso de Psicología Ambiental, Almería, febrero del 2011).

2 Autores adscritos a una narrativa de declive del espacio público y la vida pública como Neil Smith y Setha Low (2006) han afirmado recientemente que:

Los espacios públicos no son más, si alguna vez lo fueron, lugares democráticos donde una diversidad de personas y actividades son aceptadas y toleradas. En cambio, se han convertido en centros de comercio y consumo, así como en lugares de vigilancia política (...) Los derechos en la polis estaban altamente restringidos a una reducida y privilegiada clase social reconocida como ciudadanía libre, y muchas otras personas eran excluidas - mujeres, esclavos y el grueso de la gente común. Igualmente, la publicidad del ágora también estaba circunscrita (si bien de forma diferente) y estratificada como una expresión de relacio nes y desigualdades sociales prevalecientes. La estrecha definición de espacio público propia de la antigua Grecia puede por tanto ser, de manera inintencionadamente apropiada, fuente de inspiración para el presente, sin embargo el examen más superficial sugiere que también representa lo contrario de lo que consideramos el espacio público ideal. En la práctica, tanto en la antigua Grecia como en el mundo occidental actual, el espacio público verdadero es la excepción y no la regla (p. 4).
}

Esta aseveración matiza de forma evidente el argumento de la idealización patente del espacio público del pasado típicamente atribuida a la tesis del fin del espacio público. 
paradoja urbana propia de ciudades como Nueva York, Londres y París, en las cuales los espacios públicos parecen promover el aislamiento en medio de la multitud. Así, muestra cómo la arquitectura está tendiendo a la creación de "áreas públicas muertas" en las que las estructuras de relaciones sociales del pasado, fundamentadas en la civilidad y en sus característicos rituales y máscaras de sociabilidad, han sido reemplazadas por relaciones sociales de indiferencia, superficiales, efímeras y cívicamente no comprometidas. Agregándole a esto la observación según la cual los espacios públicos nuevos se han convertido más en espacios "de paso" que en espacios "para quedarse" (por ejemplo, los centros comerciales, donde uno/a compra, circula, sigue comprando, circula, y se va cuando deja de comprar), la conversión del espacio público en espacios vacíos, de circulación y/o consumo ha contribuido a la retracción de las personas hacia el ámbito de la individualidad, lo privado y la intimidad, para buscar en él lo que la esfera pública nos ha dejado de proporcionar.

Sin embargo, es probablemente la metáfora del parque temático la que mejor describe la concepción del espacio público contemporáneo sostenida por la tesis terminal. Michael Sorkin (1992) defiende que el urbanismo actual está basado en la creación de espacios públicos con tres características principales: 1) no tienen un lugar asociado a ellos (es decir, no son biográfica y socialmente significativos, ni poseen una identidad sustantiva enraizada en referentes culturales locales); 2) simulan las viejas formas del espacio público, pero son meros sucedáneos del mismo; y 3) se organizan y funcionan desde la obsesión por la seguridad y el control. Los nuevos espacios "públicos" según esta concepción (mercados, centros comerciales, recintos de uso colectivo en las plantas bajas de los edificios de oficinas, etc.) serían copias artificiales de espacios públicos genuinos, sin ningún sentido de la geografía y de la historia, controladas mediante personal y cámaras de vídeo-vigilancia para asegurar que las personas no deseadas (porque no consumen o porque son socialmente discriminadas) no puedan entrar.

Trevor Boddy (1992), por su parte, observa las características anteriores condensadas en lo que él denomina "ciudades análogas". El autor describe cómo, en varias ciudades de EEUU y Canadá, ha proliferado el desarrollo de espacios de uso colectivo compuestos por corredores aéreos cerrados y pasillos y recintos subterráneos, promoviendo y garantizando la ausencia de contacto entre los "peligros" de la calle y la actividad "segura" en estos espacios de consumo dirigidos a las clases medias blancas. El resultado de esta configuración urbanística paralela es la segregación y la pérdida de diversidad pública en las calles ${ }^{3}$. En términos de Boddy, "las pasarelas aéreas y los tú-

\footnotetext{
3 No obstante, Boddy señala que las consecuencias segregacionistas de las ciudades análogas no fueron intencionadas en un origen. De forma sugerente, sostiene que fueron un efecto de la estratificación social y racial derivada de cambios radicales provocados por las políticas neoliberales en su impacto sobre las estrategias de inversión pública, modificando así claramente la cultura y la composición de la calle.
} 
neles son la vanguardia de uno de los procesos urbanos más importantes de los 90: la transformación de los centros urbanos en suburbios" ${ }^{4}$ (p. 171).

La descripción más cruda de este espacio para-público obsesionado por la seguridad la proporciona Mike Davis (1992) en su reflexión sobre los procesos de "militarización” del espacio público. Con esta expresión, Davis pretende denunciar la tendencia paranoide a panoptizar la ciudad mediante dispositivos de control y castigo, con muros, vallas, cámaras de vídeo-vigilancia y seguridad privada, destinados a proteger a las clases acomodadas de la fantasía de un atacante omnipresente cuya amenaza es eludida mediante la reclusión en recintos privados hiper-fortificados. Davis se refiere a este aniquilamiento del espacio público en su ya célebre sentencia: "La consecuencia generalizada de esta cruzada para hacer la ciudad segura es la destrucción de cualquier espacio público auténticamente democrático" (p. 178). Más ejemplos de este augurio terminal son el análisis de Margaret Crawford (1992) sobre el centro comercial como ideal de espacio público homogeneizador y socialmente "higienizador" que mantiene excluidos a grupos de "indeseables", así como las tendencias negativas del "urbanismo neoliberal" descritas por Neil Smith (2005).

Tomadas en conjunto, las aportaciones alineadas con el discurso del fin del espacio público perfilan un diagnóstico terminal, apoyando implícitamente la idea de que de algún modo el espacio público realmente estaba vivo en algún momento del pasado. Sin embargo, este retrato apocalíptico del presente por contraste con un tiempo pretérito indefinido es criticable en la medida en que infravalora las múltiples formas de resistencia social que buscan subvertir el aniquilamiento del espacio público, y por lo tanto ignora los componentes estructurales del conflicto social que sostienen el orden socio-espacial dominante en la ciudad. Hay de hecho una incesante y tenaz actividad de contestación en el espacio público por parte de colectivos disconformes con las tendencias urbanicidas contemporáneas, tan persistentes como las dinámicas espontáneas, imprevistas o inevitables desplegadas en el espacio público surgidas de formas variadas de imaginar, necesitar y requerir el espacio abierto de la ciudad. Es precisamente este foco en la naturaleza dialéctica y conflictiva del espacio público lo que caracteriza a la perspectiva conflictivista.

\section{La tesis conflictivista}

Esta perspectiva plantea que el espacio público no ha muerto, simplemente porque nunca ha existido como tal, incluso desde el ágora griega, paradigma ficticio de un es-

\footnotetext{
${ }^{4}$ La palabra 'suburbio' traducida del inglés no significa aquí un núcleo de población periférico respecto de la ciudad cuyo componente social es necesariamente población pobre y marginada, sino cualquier núcleo residencial periférico.
} 
pacio público idealmente democrático definido por la inclusión social absoluta. Si bien el argumento según el cual el carácter estrictamente público del espacio público nunca fue completo del todo es tímidamente aceptado por las tesis optimista (Brill, 1989) y terminal (Smith y Low, 2006), la tesis conflictivista defiende de forma radical que el espacio público siempre ha estado fundamentado en alguna forma de exclusión social (esclavos, mujeres, niños, extranjeros, bárbaros, indígenas, negros, clase obrera, indigentes, inmigrantes, adolescentes alternativos, okupas, drogadictos, homosexuales, prostitutas, skaters, movimientos sociales, etc.). La exclusión, y más concretamente, las luchas de los sectores excluidos por ser incluidos y aceptados como públicos legítimos, son condiciones estructurales del espacio público.

De acuerdo con esta perspectiva, el derecho a la ciudad se fundamenta en la paradójica distribución desigual de un derecho naturalizado a excluir (Staeheli y Mitchell, 2008). Así, el espacio urbano sólo es público cuando los sectores sociales más desfavorecidos, percibidos por la imaginación dominante como social y espacialmente excluibles, se apropian del territorio urbano, lo ocupan y lo toman haciendo visibles y reconocibles sus reivindicaciones y necesidades, o cuando emergen usos espaciales espontáneos e imprevisibles (Cottino, 2003), no mediados por el Estado ni el mercado. En este proceso de conquista y libre apropiación del espacio público - proceso que convierte el espacio público en un lugar auténticamente público-, el espacio no sólo es repensado simbólicamente, sino que es producido materialmente: deja de ser un escenario para la visibilización de la exclusión, la desigualdad, la resistencia política y la imprevisibilidad urbana, para convertirse en un medio y en un producto materiales de esas reivindicaciones y manifestaciones del derecho a la ciudad (Lefebvre, 1968; Mitchell, 2003). Ello tiene lugar mediante ocupaciones de espacios vacíos que pasan a ser autogestionados, barricadas en las calles, graffiti, prácticas no regladas de comercio callejero, uso del espacio público para dormir, orinar o lavarse, trabajo sexual como elección profesional o práctica de supervivencia, plantación espontánea de huertos urbanos, etc.

La irrupción e inmediata censura de estos usos y prácticas en el espacio público revela que la esfera pública está basada en la confrontación entre públicos y contrapúblicos que pugnan por reproducir o desafiar una concepción dominante de las relaciones sociales en la que tales comportamientos espacializados no tienen cabida (Fraser, 1990; Mitchell, 1995). Existe un conflicto social estructural que adopta un aspecto material cuando se manifiesta en disputas concretas en el espacio público de la ciudad. En definitiva, según esta perspectiva, el conflicto y la contestación son motores fundamentales de la vida pública en el espacio público. Éste último se concibe como el territorio natural para la expresión y materialización del derecho a la ciudad: el derecho a 
apropiarse libremente del espacio público para visibilizar y revertir una situación de necesidad o de privación, para desplegar una opción política antagonista o para practicar una manera institucionalmente no reglada o no capturada por el capital de recrear vínculos de socialidad, a través de estrategias no mediadas y fuera de la lógica dominante del valor de cambio. El derecho a la ciudad implica necesariamente la posibilidad de tornar público el espacio urbano. En el plano territorial, es el derecho a tener lugar, es decir, a caber físicamente en el espacio público: a no ser desplazado/a, instigado/a a ocultarse, confinado/a al espacio privado, segregado/a, perseguido/a, capturado/a o expulsado/a. En el plano social, es el derecho a tener un lugar en el espacio público, es decir, a ser aceptado/a y reconocido/a positivamente como un/a habitante legítimo/a de la esfera pública entre otros/as (Barnes, Auburn y Lea, 2004). En el plano político, es el derecho a hacerse un lugar en el espacio público, es decir, a crear las condiciones materiales y relacionales para producir un cambio de signo emancipatorio en la esfera pública (Di Masso, 2015). A diferencia de la tesis optimista, para la cual el conflicto en el espacio público es una circunstancia habitual pero anómala y resoluble, y de la tesis terminal, que descuida el valor central de conflicto en el funcionamiento de la vida pública, la tesis conflictivista sitúa en el núcleo ontológico del espacio público la dialéctica de dominación y contestación, poder y resistencia, orden y transgresión, inclusión y exclusión, entre públicos y contra-públicos en situación de desigualdad.

El discurso propuesto por la tesis conflictivista, claramente minoritario frente a la hegemonía del discurso optimista y a la crítica nostálgico-derrotista del discurso terminal ${ }^{5}$, contribuye entonces a normalizar el conflicto socio-espacial y a visibilizar las políticas naturalizadas de exclusión social que sustentan el ideal normativo del espacio público (Delgado, 2011). Éste se sitúa en las antípodas de las acostumbradas prácticas cotidianas de discriminación e injusticia social, las cuales son recurrentemente sobrellevadas, contestadas y/o resistidas a través de una infinitud de "tácticas" socioespaciales (De Certeau, 1994/1999) desplegadas a diario por actores urbanos espontáneos, informales o perseguidos. Al tratarse de la perspectiva que mejor se acomoda a la exploración de la naturaleza política del espacio público, le dedicaremos un epígrafe completo más adelante.

\footnotetext{
Debe entenderse la distinción entre las tres tesis propuestas como una tentativa de identificar discursos diferenciados en torno al espacio público que, en ocasiones, no obstante, se entrecruzan. Por ejemplo, la diatriba contra los procesos de privatización y de control creciente del espacio público son comunes a la tesis terminal y a la conflictivista, apareciendo apenas como una crítica tenue en los discursos optimistas. Asimismo, la resistencia a la idealización del espacio público del pasado es más patente en las tesis optimista y conflictivista que en la terminal. Más que ser clasificaciones estancas, estas tres tendencias discursivas tienen valor heurístico para interpretar la teoría social que está implícita en los estudios sobre el espacio público (más funcionalista la tesis optimista, más marxista-crítica la conflictivista, y más crítica que marxista o incluso postmoderna la terminal).
} 


\section{El espacio público: Acotación conceptual}

La ordenación del debate intelectual sobre el espacio público en torno a tres tendencias discursivas puede resultar útil para identificar posturas evaluativas dispares y apuestas teóricas de peso político diferente. No obstante, la discusión hasta este punto todavía da por supuesto el espacio público como referente del debate, por lo que respecta a su acotación semántica, su caracterización, sus funciones y su relación con lo político (en la medida en que el espacio público es un territorio primario de la vida social en común). En este sentido, parece conveniente tratar de definir el espacio público, aunque sea tentativamente, y para ello puede resultar adecuado adoptar un enfoque pragmático: ¿De qué se habla cuando se habla de espacio público? Y en su forma negativa: ¿De qué no se habla cuando se habla de espacio público? Estas preguntas permiten abrir la discusión acerca de los límites conceptuales del término y de sus usos contestados en los contextos discursivos y sociales en los que se emplea.

\section{Definiciones tentativas}

Los espacios públicos son entornos localizados principalmente en la geografía urbana (calles, plazas, parques, mercados, etc.) pero también en áreas más o menos naturales (zonas boscosas, playas, áreas de montaña, espacios naturales protegidos, etc.). Suelen ser espacios físicamente abiertos, aunque no necesariamente. Desde el punto de vista material, un espacio público suele exigir un emplazamiento geográfico, es decir, un territorio tangible físicamente delimitado y transitable con el cuerpo. No obstante, como vimos en el caso de la perspectiva optimista, en algunas ocasiones se considera que el espacio público puede prescindir de la geografía e incluir cualquier entorno virtual de concurrencia libre y abierta en el dominio público (por ejemplo, Internet o las redes sociales virtuales). Más allá de su habitual soporte geográfico, desde el punto de vista ontológico, un espacio público es un entorno resultante de una serie de ensamblajes emergentes, fugaces e inestables entre aspectos y propiedades de materialidad variable, incluyendo vacío físico, construcciones edificatorias, objetos, cuerpos, discursos, afectos, prácticas, movimientos, normativas, tecnologías, olores, sonidos, etc. (Di Masso y Dixon, 2015; Farías y Bender, 2010; Massumi, 2002). Así, el espacio público es un tipo de lugar materialmente cambiante y temporalmente progresivo (Massey, 1994), una realidad que, desde el anclaje habitual en un emplazamiento geográfico acotado, deviene y se reconfigura permanentemente a medida que se re-articulan sus aspectos y propiedades concurrentes de manera variable e imprevisible.

Desde el punto de vista axiológico, el espacio público forma parte de las complejas dinámicas típicamente modernas de la vida pública. Ésta se compone de un tejido 
de organizaciones, entornos, prácticas y relaciones sociales fomentados, protegidos, garantizados y regulados desde las premisas ideológicas del interés colectivo y del bien común como postulados, en general, por parte de las instituciones de gobierno de los Estados y las ciudades y, en algunas ocasiones, de manera cooperativa y socialmente distribuida desde lógicas de lo público no institucionales y resignificadas como el cuidado colectivo de lo común (commons). El espacio público, por lo tanto, tiene una dimensión intrínsecamente política, ya sea desde una concepción liberal moderna como esfera pública deliberativa entre (supuestos) iguales (Arendt, 1958/2005; Habermas, 1989), ya sea desde una definición comunitarista o abiertamente crítica, materialista y dialéctica (marxista o post-marxista) (Fraser, 1990). Teniendo en cuenta esta consideración y las anteriores, y dejando al margen los entornos virtuales no territoriales, podemos definir el espacio público como cualquier forma geográficamente localizada de vida pública, donde se despliegan formas de convivencia más o menos organizadas o espontáneas y relevantes para el orden social.

Las definiciones genéricas del espacio público son sin embargo numerosas y variadas. En palabras de Stephen Carr et al. (1992):

El espacio público es el escenario donde se despliega el drama de la vida en común, (...) el terreno común donde la gente realiza las actividades funcionales y rituales que unen a la comunidad, ya sea en las rutinas normales de la vida cotidiana o en festividades periódicas. (p. 3)

Para estos autores, el espacio público se presenta habitualmente como una combinación de actividades públicas y privadas, si bien consideran que "la existencia de alguna forma de vida pública es un prerrequisito para el desarrollo de espacios públicos" (p. 22). De hecho, el funcionamiento óptimo de la vida pública depende de manera importante de contextos sociales y políticos que apoyen el desarrollo de buenos espacios públicos.

Otras propuestas han destacado el tipo de actividades y propiedades de los espacios públicos. En su ensayo sobre "la vida entre edificios", Jan Gehl (2001) establece una triple tipología de actividades que definen los espacios públicos de la ciudad como entornos significativos y atractivos. Las personas realizamos "actividades necesarias" consideradas inevitables, tales como ir a la escuela, ir a trabajar, esperar el autobús o comprar comida. También es probable que elijamos algunas actividades entre un rango de posibilidades que nos ofrecen los espacios públicos, por ejemplo, ir a pasear al parque o leer el diario en un banco ("actividades opcionales"). Por último, la vida entre edificios está muy asociada a la interacción y el encuentro con otras personas, siendo las "actividades sociales" aquéllas definidas por requerir la presencia y la implicación 
de otras personas para poder producirse (encontrarse en una esquina, conversar, mirar a la gente pasar, etc.).

Se habla también de los espacios públicos como entornos "de mente abierta" (Walzer, 1986), lo cual significa que siempre funcionan bajo un mínimo nivel de diversidad, incertidumbre y cambio, acomodando una variedad de personas y funciones no equiparable a otros entornos (el espacio doméstico, edificios privados, recintos comunitarios vallados y controlados, etc.). Leanne Rivlin (1994) observa que la diversidad y la libertad de elección son cualidades esenciales de la vida pública en el espacio público, siendo la libertad de acción uno de sus principales requerimientos y consecuencias. Sin embargo, la libertad en el espacio público está limitada por demandas variables de seguridad y, sobre todo, por imperativos culturales de orden y decoro morales (Dixon, Levine y McAuley, 2006). La seguridad es una de las cuestiones subrayadas por Jane Jacobs (1961) cuando describe la vida callejera como el lugar primario de relación social. De acuerdo con esta autora, para ser seguras las calles deben albergar una densidad constante de usos, tener "ojos sobre ella" (tanto de usuarios habituales como de peatones ocasionales) y comunicar claramente la distinción entre espacios públicos y privados.

Desde el punto de vista de sus cualidades y virtudes ideales, el espacio público se concibe como un entorno que debe ser a la vez socialmente sensible o responsivo, democrático y significativo (Carr et al., 1992). La sensibilidad se relaciona con la capacidad de responder a las necesidades y deseos de la población que va a usar esos espacios, por ejemplo, situando áreas de juego infantil en barrios donde no hay equipamientos para los más pequeños. El carácter democrático del espacio público remite a su potencial para permitir el ejercicio de los derechos de cualquier persona que vive en la ciudad, desde la expresión del disentimiento político hasta usos inscritos en estrategias de subsistencia como dormir en la calle. Además, los espacios públicos deben ser capaces de permitir a las personas establecer lazos significativos con la propia biografía, con otros grupos sociales, con la comunidad ${ }^{6}$ y con la cultura y la sociedad más ampliamente.

Complementando esta caracterización ideal encontramos múltiples propuestas de criterios de intervención en el espacio público orientadas a optimizar sus usos y a compatibilizar preferencias, todas ellas derivadas de trabajos empíricos. En esta línea, se suele afirmar que los espacios públicos funcionan mejor cuando han sido socialmente apropiados por sus usuarios (Abbu-Ghazzeh, 1996; Garcia-Ramon, Ortiz y Prats,

\footnotetext{
${ }^{6}$ Es probable que el concepto de comunidad tenga mayor resonancia con las formas organizativas de la vida social en ciudades norteamericanas, inglesas o suramericanas que en ciudades europeas continentales, y que, por lo tanto, tenga mayor o menor centralidad en los debates sobre el espacio público en un lugar u otro.
} 
2004; Ortiz, 2006); cuando están limpios y son percibidos como saludables, promoviendo experiencias de serenidad y evitando el hacinamiento y la contaminación (Arefi y Myers, 2003); y cuando garantizan la accesibilidad funcional más allá de las características particulares de sus usuarios (Pasagoullari y Doratli, 2004). De acuerdo con otros autores, los espacios públicos están directamente relacionados con la promoción de bienestar social en la medida en que facilitan experiencias de alivio frente a las rutinas diarias, fortaleciendo los lazos sociales y el sentimiento de pertenencia (Cattel, Dines, Gesler y Curtis, 2008). Además, se afirma que las personas prefieren residir cerca de espacios públicos (Wu y Plantinga, 2003) y que esta relación de proximidad física provoca que dichos espacios funcionen mejor (es decir, que sean más concurridos y elegidos para pasar tiempo de ocio). Asimismo, se considera que la naturaleza y los elementos ecológicos son importantes aspectos de diseño del espacio público que los hace más atractivos y deseables (Ward Thompson, 2002). En conjunto, estas contribuciones parecen sugerir que el bienestar de una sociedad también puede ser juzgado en base a la calidad y el funcionamiento de sus espacios públicos.

Otra aportación sugerente para caracterizar los espacios públicos frente a otro tipo de entornos es la que proporciona Brill (1989) al oponer los espacios públicos a los espacios de barrio o de vida social comunitaria. Este autor reflexiona sobre cómo ha ido variando históricamente la interrelación entre espacio público y vida pública, concluyendo que buena parte de una supuesta nostalgia actual por espacios públicos ideales del pasado se basa en una confusión entre espacios públicos y espacios comunitarios o vecinales. En los primeros, "la vida pública es claramente entre extraños y basada en la expectación y la observación, mientras que en la vida vecinal las personas no son desconocidas y predomina la interacción verbal" (Brill, 1989, p. 25). Basándose en esta distinción, Brill señala que es la vida vecinal o comunitaria la que estaría hoy en vías de extinción, luchando contra unos principios económicos de organización social que estarían acabando con las interacciones personales, cálidas, únicas y cara a cara propias de los vínculos primarios de la comunidad o el vecindario.

La presencia de extraños como elemento definitorio del espacio público destaca en otro conjunto de reflexiones sobre la ciudad. Jane Jacobs (1961) advirtió que:

Las ciudades no son como los pueblos, pero mayores. No son como los suburbios o urbanizaciones, pero más densas. Son diferentes de pueblos y urbanizaciones en cuestiones básicas, y una de éstas es que las ciudades están, por definición, llenas de extraños. Para cualquier persona, los extraños son mucho más comunes en las grandes ciudades que los conocidos. (p. 30)

Enfatizando el carácter invariable de esta circunstancia, Zygmunt Bauman (2006) afirma que "sea cual sea el futuro de las ciudades (...) siempre habrá una característica 
que permanecerá estable: las ciudades son lugares repletos de gente desconocida que convive en estrecha proximidad" (p. 26). El espacio público es entonces el locus de un mundo de extraños (Lofland, 1998). El extraño es la persona completamente desconocida a nivel biográfico, pero de quien podemos conocer cosas a partir de claves socioidentitarias proporcionadas por la forma de vestir, el tipo de comportamiento visible, las personas que la acompañan o el lugar por el que se mueve en la ciudad. El extraño es también esa persona a quien estamos unidos por interacciones cotidianas caracterizadas por una experiencia ambivalente de distancia y cercanía simultáneas (Simmel, 1950). Se trata de un "extraño familiar" (Milgram, 1970) cuya presencia asumimos y advertimos cotidianamente, pero sin implicarnos en una interacción directa con él/ella. Sin embargo, la omnipresencia del extraño como rasgo esencial del espacio público en la ciudad ha sido también matizada por quienes han argumentado que incluso en las ciudades más grandes persisten dinámicas de vida pública gobernadas por vínculos de conocimiento personal, cercano, trato directo y afecto en un tejido de identificaciones sociales con una comunidad más amplia (Fischer, 1981; Stone, 1954).

Finalmente, desde el punto de vista de sus funciones los espacios públicos permiten que el individuo se articule con la sociedad más ampliamente; que grupos y multitudes se reúnan para la acción colectiva; que los gobiernos proyecten y ejerzan poder simbólico y material; que las personas se impliquen en procesos de socialización en la vida urbana donde se interiorizan, reproducen, cuestionan y subvierten los límites del comportamiento (in)apropiado, junto con sus valores subyacentes; que se ofrezca espectáculo y entretenimiento y que las personas puedan relajarse y buscar experiencias placenteras y restauradoras para el bienestar subjetivo (Carr et al., 1992). En resumen, el espacio público debe ser capaz de albergar funciones sociales tan diversas como el encuentro social, el aislamiento en la multitud, la relajación, el entretenimiento, la venta y el consumo (reglados o no reglados), la protesta y la deliberación políticas, la supervivencia y la expresión artística (Neal, 2010).

\section{La definición del espacio público como ideal normativo: características principales}

Las aproximaciones variadas a la definición del espacio público expuestas hasta este punto demandan una caracterización sintética que resulte comprehensiva en lo conceptual y útil en la práctica, aun a riesgo de contribuir a la fantasía de que existe una definición correcta sobre las cosas o de excluir otras caracterizaciones seguramente más atinadas. Así, partimos de la definición de Zachary P. Neal (2010), para quien los espacios públicos son "todas aquellas áreas que están abiertas y son accesibles a todos los miembros del público en una sociedad, en principio pero no necesariamente en la 
práctica” (p. 1). La virtud de esta definición es doble. En primer lugar, señala dos de las características básicas del espacio público como desiderátum democrático: su apertura (en el plano espacial) y su accesibilidad a todos los públicos (en el plano social). En segundo lugar, muestra las contradicciones internas a la propia definición, la cual señala al mismo tiempo las características normativas del espacio público (apertura y accesibilidad) y su vulneración de facto como rasgos principales ("en principio, pero no necesariamente en la práctica"). Dicho de otro modo, según esta sugerente definición el espacio público es y no es al mismo tiempo aquello que se define.

En su disertación crítica sobre el espacio público en perspectiva neo-marxista, Don Mitchell $(1995,2003)$ desarrolla esta contradicción refiriéndose al espacio público como un "ideal normativo" firmemente anclado en el imaginario social. El espacio público aparece representado insistentemente como una categoría aparentemente a-problemática, tras cuyo aspecto de armonía en la convivencia social y de placidez democrática se ocultan y resuelven imaginariamente conflictos sociales profundos que se manifiestan tenazmente en la realidad práctica de espacios públicos concretos. La máxima de sentido común que ilustra este argumento se expresa en la frase habitual "el espacio público es el espacio de todos”, cuyo significado colapsa inmediatamente a la luz de situaciones cotidianas de discriminación como la persecución de personas inmigradas en la calle, la sanción a personas sin techo, las redadas a trabajadoras sexuales, la censura de determinadas prácticas económicas o la vigilancia de actividades callejeras no previstas. Por esta razón, la definición paradójica de Neal parece particularmente adecuada, al reunir al mismo tiempo el ideal normativo de apertura y accesibilidad absolutas del espacio público y su socavación sistemática en la práctica urbana territorializada.

Inspirándonos en Neal (2010), en Mitchell (2003), en algunas de las aportaciones resumidas en el apartado anterior (Brill, 1989; Carr et al., 1992; Lynch, 1981; Rivlin, 1994) y en otras teorizaciones sobre el espacio público (ver Hou, 2010; Khon, 2004; Low y Smith, 2006; Zukin, 1995), a continuación presentamos cinco características que definen idealmente un espacio público y detallamos el tipo de contradicción práctica intrínseca a cada una de ellas. En el marco de esta definición estructuralmente contradictoria, entenderemos que la deseabilidad del ideal normativo puede coexistir con su problematización a la luz de los procesos sociales espacializados que lo socavan, en la medida en que el conflicto entre dicho ideal y su ruptura se sitúa dialécticamente en la naturaleza misma del espacio público tardo-moderno.

La primera característica atribuida al espacio público es su titularidad pública. Como apunta Margaret Kohn (2004), se suele dar por supuesto que lo propio del espacio público es que legal y jurídicamente sea propiedad del Estado, el cual debe, por lo 
tanto, velar por su construcción, su gestión y su regulación como ámbito específico de la esfera pública, en ejercicio legítimo del mandato democrático de la ciudadanía como beneficiaria del mismo. En el marco de esta suposición, se entendería que un centro comercial o un cine no serían espacios públicos, sino espacios de uso colectivo, pero de titularidad privada. Igualmente, los espacios de autogestión comunitaria (por ejemplo, un huerto urbano ocupado) no serían propiamente un espacio público tampoco, a no ser que "lo público" se entienda fuera del marco de las instituciones modernas de gobierno de lo común. La publicidad del espacio público, de acuerdo con el criterio de titularidad, restringe su significado a un ámbito exterior tanto a los principios de la propiedad privada como a los de apropiación y gestión directa del espacio urbano por parte de colectivos particulares al margen del Estado.

Como segunda característica fundamental, al espacio público se le presupone una accesibilidad universal, es decir, se asume que cualquier persona debe ser capaz de entrar en un espacio público sin impedimentos o precauciones de ninguna clase. Esta característica alude a aspectos constructivos (barreras arquitectónicas tales como vallas, falta de rampas de acceso o de elementos de orientación para personas funcionalmente diversas, etc.), aspectos sociales (grupos que toman el espacio para uso propio y excluyente) y aspectos simbólicos (signos que disuaden de entrar, o significados culturalmente atribuidos al lugar que organizan simbólicamente el acceso y su denegación a través de la fuerza de normas sociales implícitas, por ejemplo, un barrio "de elite" o una plaza de la que se dice que "te roban"). La accesibilidad universal remite así a un máximo grado de permeabilidad social sobre el supuesto de la diversidad y la heterogeneidad de públicos posibles.

En tercer lugar, la libertad de uso se sitúa en el núcleo del espacio público como ideal normativo. Una vez garantizada la accesibilidad a todos los públicos, en el interior de cualquier espacio público, uno/a debe ser capaz básicamente de hacer lo que quiera, dando por supuesto que las personas comparten el conocimiento sobre los límites "normales" de esa libertad y se conforman con los mismos (límites que son controvertidos, como veremos más adelante). Según este criterio, en un espacio verdaderamente público las personas tenemos que poder descansar si queremos descansar, hacer ejercicio si lo deseamos, simplemente estar-ahí con los amigos si nos apetece, etc. Si la libertad es un componente nuclear de la modernidad, como lo es el ámbito de una esfera pública imaginariamente igualitaria, es lógico que el espacio público sea un escenario donde poder ejercer sin trabas esa libertad individual. Desde este punto de vista, no poder descansar cuando uno lo desea porque hay gente haciendo cosas que lo impiden, o no poder estar-ahí con los amigos porque no hay bancos ni sombras o hay poli- 
cía que vigila a "los jóvenes en la plaza", serían situaciones que restarían publicidad al espacio público.

Una cuarta característica del espacio público idealizado, más asumida en el discurso de las ciencias sociales que en el sentido común, remite a la posibilidad de una apropiación espontánea del espacio urbano. Lo propio de un espacio público no es sólo que cualquier persona pueda acceder al mismo y lo pueda usar libremente, sino que también pueda tomarlo para sí durante un tiempo e incluso modificarlo materialmente si la situación lo requiere (Carr et al., 1992; Lynch, 1981; Rivlin, 1994). Desde esta pers pectiva, deberían ser circunstancias normales usar una plaza para jugar un partido de fútbol, montar una charla abierta contra las políticas del gobierno, mover los bancos para poder hablar con calma o plantar un huerto comunitario. En todos estos ejemplos, el espacio es apropiado materialmente por un conjunto reducido del "público" para hacer del mismo un uso colectivo transitorio, a partir de los designios y deseos de sus propios participantes, sin prerrogativas institucionales ni guiones normativos previos (seguramente sí consecuenciales, no obstante). Esta característica es muy cercana a la concepción materialista del "derecho a la ciudad" desarrollada por Henri Lefebvre (1968) y re-elaborado por Mitchell $(1995,2003)$ a propósito de las luchas cotidianas por el espacio público. En definitiva, la apropiación espontánea del espacio público implica el derecho a hacer un uso para sí de lo público de forma temporal, implicando la posibilidad de actuar materialmente sobre la forma urbana como obra ciudadana colectiva y no planificada.

Finalmente, una característica básica del espacio público normativo, aunque extrañamente poco desarrollada (ver Borja y Muxí, 2003, o Painter y Philo, 1995, como excepciones ejemplares), es que debe garantizar el ejercicio de la condición ciudadana. Se tiende a asumir que el espacio público es el escenario natural para el despliegue material y simbólico de las prácticas que construyen y expresan la ciudadanía. Sin embargo, la cuestión ciudadana puede ser entendida de maneras muy dispares, desde las perspectivas liberales alineadas con la definición hegemónica de la esfera pública como entorno político deliberativo fundamentado en el cultivo del consenso y de un supuesto bien común, hasta concepciones críticas que destacan la naturaleza internamente conflictiva de la categoría "ciudadanía" y de las configuraciones de relaciones de poder que se sustentan y desafían en su nombre a nivel institucional y cotidiano (Di Masso, 2012). En este último sentido - y en línea con la crítica al "ciudadanismo" (Delgado, 2011; 2016) como subterfugio ideológico destinado a legitimar prácticas de expropiación democrática y de vejación de derechos elementales a personas abyectas al ámbito de los no-derechos, así como a pacificar y mistificar conflictos sociales en nombre de la democracia entendida como mero consenso-, el espacio público se sigue pre- 
sentando materialmente, no obstante, como el lugar en el que se redefine, se afirma, se negocia, se disputa y se niega esa condición ciudadana internamente tensionada en el día a día, mediante prácticas tales como llevar a los/las hijos/as a un parque para que se diviertan, participar en una protesta política, vender gafas de sol expuestas sobre una sábana o perseguir a las personas que venden estas gafas. Vale aquí el doble significado del concepto de "performación", como "actuación" y como "efecto de la actuación”. Antes de su pacificación y su censura ciudadanistas, y a pesar de las mismas, el espacio público es el escenario contradictorio en el que actuar o realizar (to perform) formas más o menos calculadas, inciertas, imprevistas, constreñidas, conquistadas o contestatarias del derecho a la ciudad en su acepción crítica (paseando tranquilo/a, haciendo ejercicio, organizando un almuerzo popular, construyendo una barricada contra la policía o insistiendo en vender gafas sobre una sábana para sobrevivir). Simultáneamente, y en el marco restrictivo, diferenciador y subalternizante de una estructura social interseccionalmente jerarquizada a diversos niveles ("raza", clase, género, nación, etc.), al actuar la condición ciudadana uno/a también se performa como tal, es decir, deviene ciudadano/a o no como efecto de actuar y de ser tratado como si (no) lo fuera (incluyendo así performaciones ciudadanas socialmente aceptadas o no, creíbles o no, institucionalmente perseguidas o no). Desde este punto de vista, a diferencia de un espacio urbano privado, en el que los vínculos de ciudadanía son secundarios respecto de la lógica capitalista del beneficio y el derecho de admisión, lo propio de un espacio público sería (en el plano normativo) que promoviera prácticas de afirmación y resistencia ciudadanas desde una concepción internamente contestada de lo que significa la "ciudadanía", siendo esta misma redefinida por la propia práctica material de contestación (Staeheli y Thompson, 1997), y asumiendo el ejercicio conflictivo del derecho a la ciudad como obra colectiva y objeto de apropiación y transformación materiales para la emancipación (Lefebvre, 1968). En el contexto de las relaciones entre la esfera pública y la esfera privada, el espacio colectivo privado convoca a la persona a ser sujeto rentable de consumo reproductor de las lógicas del capital, mientras que el espacio público debería convocar a la persona a actuar como sujeto ciudadano y agente directo del cambio social (con o contra el Estado).

\section{El espacio público como ámbito ideológico: problematización y tensiones}

Con la excepción de la aproximación crítica a la condición ciudadana esbozada más arriba, la caracterización anterior debe interpretarse como un imperativo ideológico sistemáticamente desleal a la realidad urbana. De ahí que lo consideremos un ideal normativo, es decir, una representación drásticamente abstraída de sus condiciones so- 
ciales, materiales e institucionales de producción, de funcionamiento y de regulación. Como tal, establece un horizonte teórico al cual debe aspirar cualquier espacio público para ser considerado apropiado, correcto y aceptable. No obstante, esta representación normativa tiene en la práctica un valor ideológico de signo variable, en la medida en que siempre se pone en circulación en el interior de una política de representación específica que produce efectos materiales y sociales concretos. Cualquier política de representación, al afirmar un estándar normativo ("el espacio público debe ser..."), automáticamente excluye del campo de lo conveniente, lo legítimo, lo aceptable o lo pensable otras representaciones posibles (no-normativas, o contra-normativas). Así, el valor ideológico del espacio público, como discurso y como práctica urbanística, está delimitado por las lógicas de violencia simbólica propias de cualquier disputa en el terreno de la significación (Eagleton, 1991), disputa siempre orientada a gobernar el terreno de las interpretaciones posibles de un objeto, y por tanto a consolidarse como representación hegemónica en un entramado de relaciones de poder y conflicto (Augoustinos, 1998). Sin embargo, más allá de las necesarias consideraciones relativas al ámbito de lo simbólico, el valor ideológico de cualquier discurso o acción material en nombre del "espacio público" deriva fundamentalmente de la articulación entre dos elementos clave de cualquier política de representación: su definición normativa y sus prácticas materiales y efectivas de aplicación (institucionales, espaciales, legales, económicas, tecnológicas, corporales, etc.). En consecuencia, el ideal normativo del espacio público (universal y teórico), difícilmente resiste a un análisis ideológico de los procesos discursivos y socio-espaciales desplegados sobre espacios públicos concretos (específicos y prácticos), procesos que socavan el ideal visibilizando las fracturas y contradicciones en torno a las cuales se organiza la vida social "real" en el espacio público (ver Delgado, 2011). Por "análisis ideológico" nos referimos a examinar rigurosamente en qué medida estas características idealizadas del espacio público, al ser invocadas en el contexto de prácticas socio-espaciales concretas, resultan constatablemente funcionales para justificar y legitimar, o para socavar y deslegitimar, configuraciones particulares de relaciones de poder, privilegio y dominación que operan en el contestado dominio de "lo público", no de forma abstracta, sino plasmándose materialmente en los espacios públicos visibles de la ciudad.

En esta línea, cualquier mínimo ejercicio de deconstrucción ideológica del ideal normativo del espacio público puede cuestionar el criterio de titularidad pública como definitorio del espacio público. Al fin y al cabo, hay espacios urbanos de titularidad pública con accesibilidad restringida (colegios, solares vacíos destinados a ser edificados, huertos urbanos, etc.), o espacios de titularidad privada pero de uso público (plazas inmediatamente exteriores a edificios que han cedido suelo al uso ciudadano como condición para edificar), como también hay actores públicos que gestionan espacios 
urbanos de titularidad pública, pero desde criterios privados o sectoriales (otorgando licencias para terrazas de bar, vendiendo espacio a empresas constructoras inmobiliarias, etc.), o actores sociales que convierten espacios privados en entornos públicos (edificios okupados, solares auto-gestionados, etc.).

Asimismo, la accesibilidad universal es básicamente una quimera en la práctica urbana. Hay colectivos cuya presencia misma en el espacio público está sancionada y/o penada (personas inmigradas a las que el Estado niega la documentación legal para residir y trabajar, trabajadoras sexuales, personas sin techo) o cuya libertad en el espacio público está coartada por la vigilancia o la sanción social (transexuales, activistas, personas de minorías étnicas o religiosas, etc.). De igual forma, en el espacio público no es posible hacer lo que uno/a desee libremente, sino que esta libertad está supeditada a la conformidad con la máxima liberal moderna según la cual "la libertad de uno llega hasta donde empieza la del otro". Esta concepción negativa de la libertad (Berlin, 1958/2001), habitualmente no cuestionada, al estar firmemente arraigada en el sentido común, subyace ideológicamente a una política dominante de representación del comportamiento normativo en el espacio público que privilegia sistemáticamente la libertad de las clases medias, autóctonas y hombres frente a la libertad de las clases excluidas, alóctonas y mujeres, de modo que las vulneraciones de la libertad de las primeras e imputadas a las segundas son más interpretadas y sancionadas como molestias que las vulneraciones en el sentido inverso. Según esta política de representación del espacio público, el derecho a la censura moral y a la sanción social está reservado a las clases privilegiadas en detrimento de las clases desfavorecidas. ¿Acaso no se acepta más el hecho de que una persona que tiene acceso a una vivienda se queje de que hay personas "sin techo" durmiendo en la plaza frente a su vivienda, que la queja eventual de esas personas "sin techo" sobre el desprecio con el que les tratan los vecinos "normales” y la falta de respeto a su privacidad? En el imaginario urbano hegemónico, pasear y sentarse en la plaza son comportamientos significados como libres, siempre y cuando la persona no tenga aspecto de carecer de un espacio privado al que retirarse y/o parezca "problemático". En este último caso, ese mismo imaginario normaliza el ataque a la libertad de unos en protección de la de otros, haciendo que la defensa de la libertad de uso del espacio público sea menos creíble para el grupo desposeído de su legítimo derecho a la ciudad.

En la práctica, pues, la libertad de unos no termina donde comienza la de los otros, o en todo caso el recorrido hacia el límite de la libertad del otro es más largo para unos que para otros. La libertad en el espacio público se significa y funciona ideológicamente según los cuerpos e identidades sobre las que se aplique y está por lo tanto desigualmente distribuida, como lo están la capacidad de apropiación espontánea y 
las posibilidades de performación ciudadana. De no ser así, ocupar indefinidamente una plaza para exigir que dimita un parlamento entero, o lavarse en una fuente y dormir en el espacio público al no tener acceso a una vivienda propia, por ejemplo, no serían objeto de sospecha, inquietud y censura por parte de los poderes públicos. En definitiva, como afirman Joe Painter y Chris Philo (1995), algo va mal en el ámbito de la ciudadanía si una persona no puede estar tranquila en el espacio público haciendo aquello para lo cual supuestamente sirve este espacio (protestar, sobrevivir cuando se está completamente excluido/a, etc.).

En el fondo de estas contradicciones elementales entre el ideal normativo y las dinámicas concretas del espacio público reside una concepción errónea del "público" como categoría homogénea e internamente indiferenciada (Fraser, 1990). La consigna según la cual "el espacio público es de todos", o su formulación complementaria "el espacio público no es de nadie", oculta la cruda constatación de que el espacio público es de hecho más de unos que de otros, y más para unos que para otros. La noción de "público" del ideal normativo neutraliza diferencias objetivadas entre clases sociales, géneros, orientaciones sexuales, opciones políticas, procedencias nacionales, etnias, religiones o edades. Es una categoría imaginaria sustentada en una fantasía de igualitarismo que produce tres efectos ideológicos principales. Primero, niega la heterogeneidad y la estructura de desigualdades y conflictos sociales inherentes a la concepción moderna y fetichizada de lo "público". Segundo, asigna unívocamente las características ideales del espacio público (accesibilidad, libertad, apropiación, etc.) a un sector privilegiado de la población que es identificado imaginariamente con el público entero (las clases medias o socialmente incluidas, blancas, autóctonas, masculinas y heteronormativas). Y tercero, naturaliza el derecho de los sectores privilegiados a censurar moralmente y a exigir la exclusión del espacio público de los sectores más desfavorecidos, los cuales son percibidos "más como problemas para el público que como parte del mismo" (Staeheli y Thompson, 1997, p. 34). En la medida en que estos sectores expropiados del derecho a la ciudad encarnan en el imaginario normativo la amenaza a la propiedad naturalizada del espacio público por parte de los sectores privilegiados, el ejercicio de la accesibilidad, la libertad de uso y la apropiación espacial por parte de los primeros es motivo de sospecha y objeto de conquista. En definitiva, el ideal normativo del espacio público se basa en una concepción de lo público fundamentada en los mitos del consenso, la unidad y la armonía como precondiciones y destino de lo social, mientras que su problematización demanda una epistemología crítica de lo público basada en el conflicto y en la desigualdad como naturaleza misma de lo social (en el contexto capitalista actual). Esta concepción crítica comienza con la constatación, el reconocimiento y la reivindicación de que muchos actores del espacio público no son aceptados como ciudadanos comunes o como ciudadanos de ninguna clase pero están ahí, 
precisamente volviendo público el espacio, conmocionando las definiciones normativas de lo público, lo cívico y lo ciudadano con su práctica inexorable del derecho a la ciudad, y padeciendo por ello diariamente el recelo y su rechazo como infra-públicos sancionables y excluibles (ver Urzúa, 2012, para una profundización sobre el derecho a excluir a través del planeamiento y el civismo).

La idealización del espacio público se complica todavía más si consideramos la oposición entre lo público y las lógicas de captura de lo público por parte del capital privado. La relación público-privado vertebra una tensión ideológica estructural del espacio público, conectando directamente con la prevalencia de intereses de empresas privadas sobre el bien público en los espacios "públicos" de la ciudad (Arantes, Vainer y Maricato, 2000; Francis, 1989; Jackson, 1998; Mitchell, 1995). Esta tendencia privatizadora incluye la progresiva mercantilización de la vida pública mediante la creación de nodos comerciales y dominios espaciales de propiedad privada. En esta línea, cada vez con mayor frecuencia se instalan dispositivos de control y tecnologías de vigilancia, se fomenta política y mediáticamente una cultura del miedo en las calles, proliferan los marcadores territoriales y espacios defendibles (Newman, 1972) y se imponen criterios de diseño urbano rentables por encima de las necesidades, deseos, valores y demandas de las personas que usan cotidianamente el espacio público. Esta dinámica favorece así la mutación de un vínculo social libre, espontáneo y no mediado propio del espacio público en su versión idealizada, y su sustitución por un vínculo social tasado por su valor de cambio.

En este proceso, el desorden fundamental de la vida pública, entendida como matriz de intersecciones sociales imprevisibles, es reencauzado y transformado en un orden domesticado cuyo fin es la capitalización de cualquier intercambio social. El resultado es una concepción estrecha del espacio público que disfraza sus condiciones de facto como espacio privado: las reglas de acceso, la fuente y la naturaleza del control sobre la entrada al espacio, los comportamientos individuales y colectivos sancionados en lugares particulares y las normas de uso (Smith y Low, 2006) están sobre-determinados por la función comercial y por la exclusión activa o pasiva de presencias "incómodas", de modo que se proteja al consumidor medio de un "Otro amenazador" por razones de raza, clase u otro criterio de categorización social (juventud, indigencia, género, estética outsider, etc.). Muy sugerentemente, Neil Smith y Setha Low (2006) recuerdan que "es imposible concebir el espacio público hoy fuera de la generalización social del espacio privado y su desarrollo pleno como producto de la moderna sociedad capitalista” (p. 4).

La interpretación del espacio público como un ámbito de contestación ideológica permite señalar varios ejes de tensión principales asociados a las principales caracte- 
rísticas que definen el ideal normativo. En concreto, la discusión sobre la titularidad trae al frente una tensión entre los ámbitos de lo público y de lo privado en el eje de la propiedad. ¿Garantiza la titularidad pública de un espacio urbano su funcionamiento apropiado como espacio público? ¿Significa la propiedad privada de un espacio urbano abierto que éste es un espacio menos público, independientemente de la vitalidad y diversidad sociales que se observen en el mismo? Las respuestas probablemente se encuentren menos en el criterio de propiedad, no obstante, que en la capacidad y la legitimidad para exigir y ejercer los derechos de acceso, uso y apropiación intrínsecos al derecho a la ciudad (no debatibles en el caso de los espacios de propiedad privada).

Un segundo eje de tensión ideológica deriva de las disputas fácticas por la accesibilidad al espacio público. La universalidad enunciada por la máxima de sentido común "el espacio público es el espacio de todos" sucumbe a la limitación práctica del acceso a determinados grupos sociales. Así, en cuanto a la accesibilidad encontramos una contradicción entre la inclusión absoluta prometida por el ideal normativo y la exclusión de facto de determinadas personas. El espacio público no es, pues, el espacio de todos, sino que es el territorio en el que se espacializan lógicas más complejas de inclusión y exclusión social expresadas a través de disputas en torno a las normas y requisitos de accesibilidad, el diseño urbano "defendible" y el sesgo de vigilancia de públicos "incómodos" propio del ojo ciudadano prejuicioso y de la discrecionalidad, igualmente prejuiciosa, en la aplicación a pie de calle de las normativas de regulación del comportamiento en el espacio público.

En cuanto a la libertad de uso como rasgo definitorio del espacio público idealizado, planteamos que su despliegue siempre se produce en una tensión paradójica con procesos de control social. Las personas somos libres de hacer lo que queramos en el espacio público, pero en el espacio público todo no se puede hacer. Como afirmamos antes, en la esencia misma de la libertad (en su concepción negativa) reside el propio límite de la libertad del otro. El control, auto-dirigido o ejercido por el resto de ciudadanos/as o por las fuerzas del Estado, se erige así como paradójico garante del ejercicio apropiado de la libertad en el espacio público. Esta debe ser ejercida de manera adecuada y dentro de los límites, es decir, de manera controlada. En definitiva, en el núcleo ideológico del espacio público reside una contradicción entre libertad y control.

Finalmente, las posibilidades de una apropiación espontánea del espacio público están siempre enmarcadas por los protocolos institucionales de transformación del espacio público. La libre apropiación de una plaza para organizar una fiesta popular deberá ser compatible con la normativa de usos fijada para estos casos, de modo que si se produce fuera de esta normativa (porque está prohibido) o más allá de lo fijado por la misma (porque se produce en horarios no permitidos o empleando artilugios no regla- 
dos), el Estado intervendrá en calidad de autoridad para restaurar la situación (y devolverle, supuestamente, su publicidad). La situación se tensa más si un colectivo autónomo ocupa un solar público para crear un huerto comunitario y hacer activismo anarquista durante un tiempo indefinido. Probablemente esta acción de apropiación se interprete por parte de las autoridades del Estado como un desafío al orden público (orden del cual los sectores anarquistas están excluidos) y como un "problema a resolver". En estos casos, más allá de las lógicas de libertad y control propias del uso del espacio público, aparece aquí una oposición en el eje orden-desorden social, considerando que lo que se despliega y limita en el espacio público en estos casos no es tanto la libertad de uso como la capacidad de agencia política del individuo o del colectivo frente a la autoridad de Estado.

En el eje orden-desorden social, la apropiación espontánea del espacio público como recurso para el empoderamiento comunitario autónomo, el antagonismo ácrata o cualquier práctica de emancipación respecto de las lógicas institucionales (del Estado o del mercado)-, está sistemáticamente vigilada, neutralizada e incluso cooptada por estas lógicas mismas, en nombre siempre de un público identificado erróneamente con la institución y la comunidad que supuestamente lo representan (el Estado y la ciudadanía) o que buscan capitalizarlo (el mercado y el consumidor).

\section{El conflicto en el espacio público}

La caracterización del ideal normativo del espacio público y su crítica desde las contradicciones estructurales que lo socavan, nos llevan a abordar el espacio público como una realidad inestable en cuyo núcleo ontológico reside el conflicto como manifestación principal. Hablamos de conflicto y no simplemente de contradicción al considerar que el tipo de tensiones que atraviesan la vida en el espacio público traducen y vehiculan territorialmente relaciones de privilegio y subalternidad que vertebran el orden social. La privatización del espacio público y del vínculo social en el mismo, la exclusión de públicos "indeseados" (ver Berroeta y Muñoz, 2013), el control progresivo de las prácticas urbanas o la hiper-regulación institucional de lo que sucede en la calle, en detrimento de las lógicas autónomas, espontáneas y emergentes, nos dicen algo acerca de cómo opera el poder político a través de las relaciones socio-espaciales en la ciudad. $\mathrm{Al}$ considerar el conflicto como un elemento nodal del espacio público, resulta conveniente profundizar mínimamente en qué entendemos por conflicto, para lo cual retomaremos brevemente el marco "conflictivista" esbozado al inicio del artículo.

Por citar tan sólo algunas aportaciones centrales en este marco, Henri Lefebvre propuso ya a finales de los años 1960 que la convivencia urbana está caracterizada por la heterogeneidad (las personas interactuamos en medio de la diversidad social y la di- 
ferencia), la habitabilidad (la ciudad es el hábitat de la mayoría de las personas, el lugar donde vivimos permanentemente) y el conflicto (la lucha entre diferentes sectores de la sociedad en sus intentos respectivos de ejercer el derecho a la ciudad como obra colectiva). El conflicto, en la concepción de Lefebvre, se expresa cada vez que se multa a personas que venden y beben latas de cerveza en una plaza; cuando se detiene a las trabajadoras sexuales en las calles de la ciudad; cuando se persigue a personas inmigradas indocumentadas para arrestarlas y expulsarlas a "sus" países de procedencia o incluso a terceros países con los cuales se tiene convenios de expulsión; cuando un ciclista discute en la calle con un peatón que ha invadido el carril bici; cuando los movimientos sociales ocupan un solar vacío para auto-gestionarlo; o cuando los vecinos de un barrio protestan porque los jóvenes que tocan música frente a sus fachadas no les dejan descansar.

A la estela de Lefebvre, las punzantes críticas de Nancy Fraser (1990) y Don Mitchell $(1995 ; 2003)$ a la concepción burguesa dominante de la esfera pública en las democracias occidentales modernas, comparten una serie de argumentos que problematizan el núcleo de la imaginación hegemónica del espacio público capitalista. Mitchell considera que los conflictos territorializados por el derecho a la ciudad son la razón de ser del espacio público como espacio político, y a la vez son el mecanismo por antonomasia de conquista de la justicia social. Por su parte, Fraser socava los discursos sobre el espacio público subsidiarios de la teorización habermasiana sobre una democracia deliberativa supuestamente ideal, capaz de superar diferencias sociales objetivas. Según esta autora, una concepción "post-burguesa" de la esfera pública debería basarse menos en la creación de espacios materiales para la deliberación como si las desigualdades sociales no existieran, y más en las tentativas directas de eliminar dichas desigualdades. Esta nueva concepción de la esfera pública sitúa el antagonismo entre distintos sectores del "público" en el centro de los procesos políticos de una sociedad profundamente estratificada. Ello permite trabajar sobre la relación asimétrica entre públicos "fuertes" y "débiles", disolviendo las rígidas fronteras entre áreas privadas y públicas (orientadas además a la dominación masculina) en nombre de un "público" erróneamente presentado como ideal normativo de inclusión social.

Directamente inspirada en la propuesta de Fraser, Crawford (1995) subraya la crítica conflictivista de las narrativas de la pérdida propias de la tesis terminal. Esta autora aboga por re-evaluar los espacios públicos de la ciudad en términos de la diversidad de colectivos que practican sus distintas maneras de necesitar y significar el espacio urbano. En palabras de esta autora:

Las calles, aceras, parcelas vacías, parques y otros lugares de la ciudad, reclamados por grupos de inmigrantes, gente pobre y personas sin techo, se han 
convertido en lugares donde los debates públicos sobre el significado de la democracia, la naturaleza de la participación política y la afirmación pública de la identidad son actuados cotidianamente. (p. 6)

Lejos de aceptar una versión del espacio público deformada por el ideal democrático de paz y consenso, Crawford afirma que "los lugares públicos donde ocurren las luchas sirven como evidencia de un orden emergente, todavía no del todo comprensible (...) la multiplicidad y la contestación, más que constituir el fracaso del espacio público, definen de hecho su naturaleza misma" (p. 9).

En la misma línea, Lynn Staeheli y Albert Thompson (1997) proponen que la lucha material por el espacio público muchas veces traduce a un lenguaje territorial un debate político sobre los límites de la ciudadanía, la comunidad y la categoría de los públicos legítimos. En su trabajo de campo (cerca de un campus universitario en EE. UU.) reunieron las percepciones de todas las partes de alguna forma implicadas en un conflicto territorial entre residentes, policía, grupos de interés pertenecientes al mundo del negocio en la comunidad y grupos contra-culturales que fueron responsabilizados por el conflicto. Su análisis constató la importancia de las estrategias territoriales emprendidas por los grupos contra-culturales en respuesta a las medidas, también materiales, impuestas por la comunidad para prevenir o impedir la presencia de aquellos en el espacio público (ampliación de los límites de la propiedad privada en torno a los negocios, ubicación de vallas y señales de "no pasar", aprobación de nuevas reglas de acceso a recintos abiertos, etc.). Para contrarrestar estas medidas, los grupos contra-culturales ponían a prueba los límites normativos ejercidos por dichos dispositivos territoriales, traspasando áreas prohibidas, sentándose sobre las vallas o pintando graffiti (práctica antes inexistente en el barrio). Como comentan las autoras del estudio, las luchas sobre el espacio público como las de este distrito "representan una forma territorial de luchas sobre los variados significados de la ciudadanía y la pertenencia a la política” (Staeheli y Thompson, 1997, p. 32). En efecto, Staeheli y Thompson interpretan este conflicto como la expresión de una dialéctica entre la reducción de los márgenes de la ciudadanía aceptable mediante cambios y controles territoriales excluyentes en el espacio público, por un lado, y los reclamos de los grupos excluidos, expresados también espacialmente, para ser aceptados como ciudadanos legítimos sin pertenecer por ello a la comunidad dominante, por otro lado. Esta conclusión refuerza el argumento conflictivista común a Mitchell, Fraser y Crawford sobre la necesidad de concebir el "público" y la ciudadanía como categorías plurales e internamente contestadas. El derecho a la ciudad debe permitir a distintas comunidades, grupos sociales y contrapúblicos reafirmar sus identidades y revertir su desigualdad, a la vez que preservar su diferencia, a través de los usos variados y conflictivos del espacio público. 
No obstante, los contra-públicos referidos por los discursos conflictivistas no se limitan a los segmentos de población más empobrecidos. Se ha hablado también de "interacciones no mediadas" en el espacio público (Mitchell, 2003), como aquellas prácticas que discurren espontáneamente fuera de los protocolos habituales del orden socioespacial en la ciudad (por ejemplo, jugar a la pelota en las escalinatas del edificio de una biblioteca pública, o sacar las sillas a la calle una noche de verano). Desafían también la concepción dominante del espacio público los "actores informales" (Groth y Corijn, 2005) y la "ciudadanía insurgente" (Holston, 1998), gente que "cuando aparece en la ciudad (...) con sus nuevas historias, culturas y demandas, inevitablemente provocan una disrupción de las categorías normativas de la vida social y del espacio urbano" (Crawford, 1995, p. 8). Estas presencias inesperadas pueden intervenir en plazas, calles, parques o en "espacios sueltos" (Franck y Stevens, 2006). Jacqueline Groth y Eric Corijn (2005), por ejemplo, estudiaron tres experiencias de ocupación y animación de espacios indeterminados en Berlín, Helsinki y Bruselas, lugares que esperaban alojar usos estratégicos en el mercado dentro de programas más amplios de regeneración urbana y que acabaron convirtiéndose en lo que los autores denominan "constelaciones de defensa": apropiaciones espaciales que perforan el rumbo de las políticas urbanas oficiales y presionan a las instituciones desde la creatividad en una dirección no planificada, casi siempre opuesta a los designios y requerimientos de una agenda política que busca mantener dichos espacios bajo control para sacarles máxima rentabilidad.

La presencia de actores informales en lugares indeterminados es también interesante porque dice algo sobre una hipotética tendencia tardo-moderna por lo que respecta a la organización social de las luchas por el espacio público. Como señalan Groth y Corijn (2005):

El conflicto urbano en la era Fordista se daba dentro de líneas institucionales, con actores organizados y claramente definidos con posiciones antagonistas enfrentando unos con otros (...). Las agendas eran claramente predecibles. Las 'luchas' y contestaciones de hoy son tan fragmentadas, diferenciadas y contradictorias como sus agentes. (p. 505)

Parecería, pues, que el análisis del espacio público, entendido como territorio primario para la expresión del conflicto social, no debe idealizar ni sobrevalorar la capacidad auto-organizativa de los sujetos políticos que son sus protagonistas, ni atribuirles siempre altos niveles de compacidad y congruencia (ver Berroeta y Sandoval, 2014). En la holgada categoría de los contra-públicos hay diferencias esenciales entre, por ejemplo, grupos de personas sin techo, cuya transgresión espacial no suele ser en absoluto una opción, menos aún basada en un ejercicio intencionado y colectivamente organi- 
zado de su conciencia política, y activistas de orientación anarquista que luchan deliberadamente por un espacio urbano con piedras y barricadas (activistas cuyas acciones se enmarcan en la confrontación y la resistencia directas, con un fundamento social declarado y con objetivos políticos explícitos). Asimismo, no son iguales las condiciones de interpelación institucional en las deformadas democracias actuales comparadas con otros sistemas de orientación autoritaria del pasado, ni el grado de cohesión social de sociedades individualistas en relación a otras sociedades donde los vínculos de solidaridad y mutualidad están culturalmente más arraigados.

Las experiencias de contestación y conflicto en el espacio público son constantes y numerosas porque son, en definitiva, inevitables, y son inevitables porque son inherentes al tejido de relaciones de diversidad y desigualdad que componen la vida social en la ciudad. El conflicto en el espacio público permite visibilizar los fundamentos geográficos del control y la exclusión social y advertir, para luego poder subvertir, las relaciones de dominación que sostienen el orden socio-espacial en la ciudad. Es en este sentido que el espacio público es el escenario material para el cambio social y un termómetro más de la calidad democrática de una sociedad. Pruebas del carácter inagotable del conflicto urbano son la emergencia permanente de conflictos en lugares públicos que simbolizan poder político (Jeong y Almeida, 2004; Philp y Mercer, 2002); las disputas socio-espaciales que buscan desafiar las concepciones patriarcales dominantes (Amir-Ebrahimi, 2006; Bonnin, 2000; Nagar, 2000); las discrepancias ideológicas entre grupos nacionalistas y no-nacionalistas en cuanto a la interpretación y uso de edificios públicos simbólicos (Devine-Wright y Lyons, 2007; Loukaki, 1997; Stangl, 2006); los procesos de contestación de formas consolidadas de segregación racial del espacio urbano (Dixon y Durrheim, 2000; Oelofse y Dodson, 1997); o los conflictos que implican prácticas controvertidas en el espacio público desde el sentido común dominante, como beber alcohol, vender artículos fuera de la economía reglada, consumir drogas, pintar graffiti, colgar carteles o lavarse en fuentes (Cusick y Kimber, 2007; Dixon et al., 2006; Halsey y Young, 2006; Popke y Ballard, 2004; Snow y Mulcahy, 2001).

Sin necesidad de recurrir a experiencias extraídas de estudios académicos, es posible citar más ejemplos claros de conflictos del espacio público en la vida cotidiana, que destapan la resistencia de los poderes públicos y privados ante formas de subsistencia no regladas, comportamientos transgresores o prácticas deliberadamente contestatarias que aparecen en el espacio público. Por ejemplo, en la ciudad de Barcelona la policía de uniforme o de civil persigue, identifica y arresta diariamente a personas inmigradas "sin papeles" por vender objetos en la calle, expulsando sus cuerpos fuera del espacio público; diariamente también personas sin techo, trabajadoras sexuales, vendedores ambulantes, jóvenes pasando el rato en bancos o patinando, activistas colgando 
carteles con convocatorias de actividades y otras tantas personas son dispersadas o multadas por "conductas incívicas", viendo reprimidas, censuradas o negadas sus opciones de subsistencia, sus usos alternativos de la calle o sus canales de comunicación política en el espacio público; periódicamente solares vacíos esperando revalorizarse en el mercado especulativo son re-apropiados por colectivos sociales para plantar huertos urbanos al margen de la lógica del mercado. El espacio público afirma y niega simultáneamente su publicidad a través del conflicto en todos estos casos.

\section{Modalidades de conflicto}

¿Cómo se han definido los tipos de conflicto en el espacio público? Una caracterización muy sugerente es la propuesta por Himanshu Burte (2003) a partir del estudio del espacio público en la India. Según este autor, el espacio público puede ser el objeto de conflictos, el escenario de conflictos o el precipitado de conflictos (frecuentemente presenta las tres facetas al mismo tiempo). Como objeto de conflictos, el espacio público suele alojar disputas en torno a sus formas de uso, modos de control y derechos de ocupación, incluyendo cuestiones como el tipo de usos y actividades (in)aceptables e (in)admisibles, la legitimidad de ciertos públicos para ocuparlo o discusiones acerca de quién debería estar autorizado a controlarlo, gestionarlo y tomar decisiones con respecto al mismo, así como bajo qué condiciones hacerlo (ver Berroeta y Muñoz, 2013, para el caso de las personas sin techo). Como escenario de conflictos, el espacio público funciona como una plataforma, tanto para las manifestaciones legítimas de disentimiento político, como para el despliegue de acciones de violencia urbana entre personas o hacia edificios y mobiliario urbano. En tercer lugar, como precipitado o sedimento de conflictos previos, el espacio público puede ser un depósito simbólico de memoria colectiva, condensando significados y valores que expresan luchas pasadas ocurridas en el espacio y que forman parte de la identidad y del pasado locales. Así, un conjunto de vecinos podría ocupar un solar urbano vacío para reivindicar la construcción de un parque o una plaza, plantando árboles y desarrollando actividades auto-gestionadas (objeto de conflicto). Ese espacio podría ser acordonado por la policía tras un enfrentamiento violento con los vecinos, que serían expulsados del espacio (escenario de conflicto). El espacio podría ser re-apropiado por los vecinos para seguir defendiéndolo hasta que los poderes públicos cedieran y aceptaran la creación de un parque. Años más tarde este espacio representaría simbólicamente la conquista barrial por un parque (precipitado de un conflicto).

La tipología de Burte nos resulta útil para comprender que el espacio público es un lugar cuyo control y uso territoriales suelen expresar relaciones sociales conflictivas, convirtiendo el espacio tanto en un recurso para ejercer poder y ofrecer resisten- 
cia, como en una plataforma necesaria para que ese poder y esa resistencia sean públicamente visibles. Esta caracterización permite trazar una segunda distinción imprescindible en el campo de los conflictos en el espacio público. Debemos considerar en primer lugar que hay conflictos que derivan de la diversidad social. Por ejemplo, una señora mayor que riñe a una chica que está orinando en la calle tras una fiesta de barrio, argumentando que "orinar en la calle es totalmente de mal gusto y que eso debe hacerlo en su casa”. Aquí se manifiesta un conflicto entre concepciones normativas dispares sobre el comportamiento de orinar en la calle como algo moralmente apropiado o inapropiado (dando así un significado concreto al espacio público). Otro ejemplo sería el del patinador adolescente que choca con un señor en una plaza, a lo cual el señor responde con insultos diciendo que "esa plaza no es para patinar" y que el joven debería irse "a otro lugar". Un tercer ejemplo lo constituirían los grupos de chicos que pelean por el uso de una pista de fútbol en un parque público. Estos tres ejemplos ilustran roces interaccionales derivados de la heterogeneidad de usos del espacio público entre categorías sociales en igualdad de estatus en el espacio social y en la imaginación dominante del derecho a la ciudad, expresando relaciones materiales de poder horizontal (heterogeneidad como diversidad). En estos casos sucede que los usos simultáneos del espacio entran en fricción por cuestiones de falta de espacio, de incompatibilidad, de excesos de tiempos normativos de uso o de juicios de inmoralidad del comportamiento.

Los conflictos derivados de la mera diversidad son de naturaleza distinta de los conflictos que se vinculan a la desigualdad social. Estos involucran a sectores del público en relación de jerarquía, dominación y subalternidad en el espacio social y en la imaginación hegemónica del derecho a la ciudad, reflejando relaciones materiales de poder vertical en el espacio social (heterogeneidad como desigualdad). Si la persona reñida por la señora mayor por orinar en la calle se trata de una persona "sin techo" en lugar de ser una adolescente, la cuestión cambia radicalmente. Lo mismo sucede cuando se detiene en la calle a personas que han inmigrado o cuando los vecinos llaman a la policía para que desalojen una plaza donde jóvenes "con aspecto latino" llevan "demasiado tiempo" fumando y "haciendo ruido" con la música. En estos casos, lo que se expresa es una asimetría en el derecho a la ciudad: un conflicto más profundo vinculado a la calidad democrática del espacio público, a la vigilancia social de los límites de la ciudadanía legítima y a los procesos políticos de exclusión social que operan a través del control territorial del espacio público urbano. Los juicios de inadecuación de tales comportamientos en el espacio público, junto con sus consiguientes prácticas formales o informales de censura y represión, funcionan en este caso como subterfugios para la reproducción de prácticas más o menos sutiles de discriminación social de tipo racista, xenófobo o clasista. Los usos "desviados" del espacio público por parte de segmentos 
sociales en circunstancias de privación severa, estigmatizados, criminalizados, en situaciones de absoluta pobreza o que simplemente aparecen en el espacio urbano haciendo "cosas" imprevistas, confirman precisamente el grado de exclusión exigido por el ideal normativo para garantizar que el espacio público "funciona bien". Por esta razón tales "problemas" o "imprevistos" despiertan tanta inquietud o indignación. Es en este punto donde se manifiesta la dialéctica política inherente al espacio público como espacio de conflicto social. Para preservar la ficción de igualitarismo, unidad y armonía en el espacio público, se vigila y se mantiene fuera del mismo aquellos usos y prácticas que corrompen el orden público hegemónico en la ciudad. Por eso el espacio público del ideal normativo no es en la práctica un espacio universalmente inclusivo (un espacio propiamente público), sino un espacio que ha logrado normalizar el orden interno de sus vigilancias y exclusiones, naturalizando el derecho a excluir por parte de un sector en nombre del público entero: un público imaginario despojado de la clase de cuerpos "malignos" que desestabilizan la ordenación jerárquica del derecho a la ciudad como campo de relaciones de privilegio y subalternidad. El espacio público propiamente público es siempre, pues, el espacio del conflicto, sea éste negado o afirmado, latente o patente, contenido o desbocado, resuelto imaginariamente o visibilizado para trabajar políticamente desde el mismo y catalizar una transformación. Cuando este proceso de represión y exclusión afecta a sectores sociales privados de mínimas condiciones de vida y a colectivos social o políticamente incómodos (¿podría funcionar en un sentido opuesto?), el espacio "público" pierde su publicidad porque el derecho a la ciudad de unos es protegido a expensas del derecho a la ciudad de otros. Así, cada vez que un inmigrante sin papeles que vende bolsos en la calle es identificado y encerrado en un centro de internamiento de extranjeros, cada vez que una persona sin techo es multada por dormir en la calle, o cada vez que activistas son detenidos por ocupar un solar y reconstruirlo, asistimos a la versión tangible de un conflicto estructural en el que intersectan el comienzo y el fin del espacio público (el uso y la censura, la apropiación y el desalojo, el orden y el desorden) (Mitchell, 2003). En ese preciso instante se pone de manifiesto el grado de exclusión social requerido por la concepción dominante del espacio "público" para garantizar sólo el derecho a la ciudad de quienes caben en los estrechos márgenes del público legítimo. Es así como el orden "normal” en el espacio público exhibe su impostora vocación democrática, vocación clasista basada en un estándar óptimo de injusticia social.

\section{Conclusiones}

El espacio público es un espejo que le devuelve a la ciudad la imagen de una sociedad contradictoria, inquietante e imprevisible, una sociedad que intenta negar sus conflic- 
tos estructurales operando sobre el espejo mismo. El ideal normativo del espacio público, como representación prescriptiva habitual, dibuja sobre el espejo la imagen de la sociedad que no es y maquilla lo que no quiere ver. En este artículo hemos abogado por una forma de entender el espacio público que problematiza este ideal normativo y que sitúa en el núcleo de su funcionamiento práctico la inestabilidad convivencial, el conflicto social y el monopolio clasista naturalizado del derecho a censurar y a excluir legítimamente. Desde esta concepción crítica, la sociedad que late bajo la ficción y el maquillaje se encarna en el territorio urbano y expone su rostro compuesto de fricciones, desigualdades y contra-propuestas urbanas, reclamando el espacio público mismo como palanca del cambio social.

La postura que asumimos invita tanto a conocer como a sospechar de cualquier aproximación al espacio público con vocación normativa, incluida por supuesto la que proponemos aquí, importada en buena medida de desarrollos teóricos y estudios empíricos en el ámbito de la geografía política y la filosofía feminista de orientación marxista. En este sentido, la afirmación según la cual el espacio público verdaderamente ideal (verdaderamente público) es el espacio en conflicto, puede resultar ciertamente descorazonadora. Al fin y al cabo, ¿no aspiramos todos/as a llevarnos bien sin necesidad de estar permanentemente luchando? ¿No estaremos pasando de idealizar la armonía y la unión a idealizar el conflicto y la discordia? Sin restarle razones inapelables al deseo de llevarnos bien y a la aspiración de alcanzar la calma social, el llamado a colocar el conflicto en el centro del espacio público responde menos a un apego sistemático a la lucha como fin en sí mismo que a la provocación de una toma de conciencia acerca de cómo el conflicto mismo, siendo inevitable como es en sociedades estructuradas por la desigualdad y la exclusión sistémicas, puede ser conceptualizado, no como un mal a eludir, sino como un medio muchas veces imprescindible para reconocer, visibilizar y trabajar otras cuestiones de profundo calado social. En definitiva, no es posible "llevarnos bien" en el espacio público sin poner antes en cuestión desde qué subjetividad y posición privilegiadas, en un entramado de relaciones de hegemonía trazables en el uso y gestión del espacio urbano, se establecen y se regulan social e institucionalmente las condiciones simbólicas y materiales de la "buena convivencia" urbana. No es posible "llevarnos bien" sin asumir el conflicto como característica inherente a las relaciones en el espacio público, sin interpretar socialmente su versatilidad geográfica y sin apostar por su vocación constructiva como catalizador de procesos materiales de transformación social.

Para finalizar, queremos señalar un riesgo y una apuesta adicionales. En primer lugar, la producción de otro texto más sobre el espacio público puede contribuir a sobrevalorar y fetichizar todavía más un ámbito de debate ya saturado de manuales, re- 
flexiones y críticas. En un momento en el que el declive de "lo público" abraza todos los ámbitos posibles de la vida (educación, sanidad, trabajo, vivienda, cultura, política, etc.), ¿por qué seguir centrándose en el espacio público como plataforma primaria para la reparación y reconstrucción de lo común en tiempos de máxima expropiación de derechos a todos los niveles? Además, en una época en la que la erosión del papel y de la legitimidad de las instituciones del Estado como garantes de lo público es máxima frente a los poderes económicos fácticos y el dominio de las instituciones supra-estatales en frecuente connivencia con aquellos, a la par que se reivindican cada vez más otras maneras de entender y practicar lo público fuera de las lógicas estatistas, ¿no estaremos errando al empecinarnos en debatir en torno a "lo público" en términos excesivamente modernos y tal vez ya caducados? En esta misma línea, ¿qué valor tienen los derechos en un mundo en el que todo el mundo sabe que tener derechos no es garantía de nada? Estos interrogantes nos parecen fundamentales y necesarios, tanto para seguir reflexionando en torno al espacio público como para justificar la conveniencia teórica y práctica de resignificar sus términos e incluso de trascenderlo como debate supuestamente relevante para pensar lo social hoy.

No obstante, el riesgo de reincidir en formas inapropiadamente modernas de pensar lo público y lo común, o de sobrevalorar el espacio público como catalizador del cambio social, no debe implicar una infra-valoración del papel indispensable que sigue jugando el espacio público como territorio material de lo común en la cultura urbana del "nuevo capitalismo" (Sennett, 2006). En primer lugar, la "ciber-fetichización" (Rendueles, 2013) propia de la era de las nuevas tecnologías está anclando en el imaginario político la idea de que los grandes cambios sociales se producirán desde y gracias a las tecnologías, en una esfera pública presuntamente etérea y meta-geográfica. Frente a este nuevo dogma, que parece expulsar el espacio físico y el mundo material de cualquier debate contundente sobre la transformación social, reivindicamos el espacio urbano como territorio indispensable para el cambio. En definitiva, tomar la calle sigue siendo igual o más importante que invadir las redes sociales, y lo sigue siendo al menos por dos motivos. Primero, para visibilizar, corporeizar y viabilizar políticamente injusticias y demandas que corren el riesgo de disolverse en el voraz entorno hiperreal de la virtualidad. No hay nada inherente a las tecnologías de la comunicación y la multi-localización instantáneas que garantice una auténtica agitación de las conciencias y un compromiso político práctico (aunque ello efectivamente se dé, y de formas extraordinariamente impactantes), e incluso nada indica que esto último sea más probable que una expansión aún mayor de la epidemia de ciber-ensimismamiento individualista y de consumo simbólico de "lo político" como signo psíquicamente gozable en la actual cultura del narcisismo. Protestar eficazmente, en términos políticos fuertes, necesita y ocupa espacio, por muy conveniente -y probablemente indispensable- que 
pueda resultar también el ciber-activismo estratégico. La corporeización y la espacialización de la protesta y la acción política permiten encarnar el poder efectivo de la multitud, interpelando a los poderes públicos y privados de una manera particularmente directa (por ejemplo, rodeando un parlamento o entrando en una entidad financiera para hacer una acción de boicot). La acción política desde el espacio e inscrita materialmente en el cuerpo social, así como sus reacciones políticas igualmente localizadas y corporeizadas, operan por debajo de la hiper-realidad a un nivel de impacto más elemental y protegido de cualquier simulacro representacional.

En segundo lugar, la lógica de acumulación por desposesión, propia del capitalismo en su fase actual, hace de las rentas monopolistas del suelo urbano un instrumento básico para la expansión y multiplicación del capital (Harvey, 1996), convirtiendo el espacio común de la ciudad en un medio de producción más, no al servicio del público sino de los intereses del mercado privado. En consecuencia, el asalto al espacio urbano para su apropiación social representa en este contexto una herramienta de resistencia política fundamental para incomodar y tratar de cortocircuitar esas vías territoriales de expropiación capitalista, reinscribiendo el espacio en una lógica de conflicto por la justicia social. El espacio público, en definitiva, no es en absoluto un espacio ni un debate trivial.

\section{Referencias}

Abu-Ghazzeh, Tawfiq (1996). Reclaiming public space: The ecology of neighborhood open spaces in the town of Abu-Nuseir, Jordan. Landscape and Urban Planning, 36(3), 197-216. https://doi.org/10.1016/s0169-2046(96)00343-x

Amir-Ebrahimi, Masserat (2006). Conquering enclosed public spaces. Cities, 23(6), 455461. https://doi.org/10.1016/j.cities.2006.08.001

Appleyard, Donald (1981). Livable streets. Berkeley: University of California Press.

Arantes, Otília; Vainer, Carlos \& Maricato, Ermínia (2000). A cidade do pensamento único. Petrópolis: Vozes.

Arefi, Mahyar \& Meyers, William (2003). What is public about public space: The case of Visakhapatnam, India. Cities, 20(5), 331-339. https://doi.org/10.1016/s02642751(03)00050-7

Arendt, Hanna (1958/2005). La condición humana. Barcelona: Paidós.

Augoustinos, Martha (1998). Social representations and ideology: towards the study of ideological representations. En Uwe Flick (Ed.), The psychology of the social (pp. 156-169). Cambridge: Cambridge University Press.

Barker, Chris \& Galasinski, Dariusz. (2001). Cultural studies and discourse analysis. London: Sage. 
Barnes, Rebecca; Auburn, Timothy \& Lea, Susan (2004). Citizenship in practice. British Journal of Social Psychology, 43(2), 187-206. https://doi.org/10.1348/0144666041501705

Bauman, Zygmunt (2006). Confianza y temor en la ciudad. Vivir con extranjeros. Barcelona: Arcadia.

Berlin, Isaiah (1958/2001). Dos conceptos de libertad y otros escritos. Madrid: Alianza.

Berroeta, Héctor \& Muñoz, María Isabel (2013). Usos y significados del espacio público en personas en situación de calle. Un estudio en Valparaíso y Viña del Mar. Revista de Psicología Universidad de Chile, 22(2), 3-17. https://doi.org/10.5354/0719-0581.2013.30849

Berroeta, Héctor \& Sandoval, Juan (2014). Protestas, participación y educación pública: Discursos sobre lo público en las movilizaciones estudiantiles en Chile. Educar em revista, 53, 19-38. https://doi.org/10.1590/0104-4060.36578

Boddy, Trevor (1992). Underground and overhead: building the analogous city. En Michael Sorkin (Ed.), Variations on a theme park. The new American city and the end of public space (pp. 123-153). New York: Hill and Wang.

Bonnin, Debby (2000). Claiming spaces, changing places: political violence and women's protests in KwaZulu-Natal. Fournal of Southern African Studies, 26(2), 289-300. https://doi.org/10.1080/03057070050010138

Borja, Jordi \& Muxí, Zaida (2003). El espacio público: Ciudad y ciudadanía. Barcelona: Electa.

Brill, Michael (1989). Transformation, nostalgia, and illusion in public life and public place. En Irwin Altman \& Ervin Zube (Eds.), Public places and spaces (pp. 730). New York: Plenum Press.

Burte, Himanshu (2003). The space of challenge: Reflections upon the relationship between public space and social conflict in contemporary Mumbai. En (In)Visible Cities. Spaces of Hope, Spaces of Citizenship. Barcelona, julio de 2003. Recuperado de: http://www.publicspace.org/es/textobiblioteca/eng/a014-the-space-of-challenge-reflections-upon-the-relationshipbetween-public-space-and-social-conflict-in-contemporary-mumbai

Carr, Steven; Francis, Mark; Rivlin, Leanne \& Stone, Andrew (1992). Public space. New York: Cambridge University Press.

Castells, Manuel (1986). La ciudad y las masas. Sociología de los movimientos sociales urbanos. Madrid: Alianza.

Cattel, Vicky; Dines, Nick; Gesler, Wil \& Curtis, Sarah (2008). Mingling, observing, and lingering: Everyday public spaces and their implications for well-being and social relations. Health \& Place, 14(3), 544-561. https://doi.org/10.1016/j.healthplace.2007.10.007

Cohen, Stanley (2002). Folk devils and moral panics. London: Routledge

Cottino, Paolo (2003). La ciudad imprevista. Barcelona: Bellaterra.

Crawford, Margaret (1992). The World in a shopping mall. En Michael Sorkin (Ed.), Variations on a theme park. The new American city and the end of public space (pp. 3-30). Hill and Wang: New York. 
Crawford, Margaret (1995). Contesting the public realm: Struggles over public space in Los Angeles. Fournal of Architectural Education, 49(1), 4-9. https://doi.org/10.2307/1425371

Cusick, Linda \& Kimber, Jo (2007). Public perceptions of public drug use in four UK urban sites. International fournal of Drug Policy, 18(1), 10-17. https://doi.org/10.1016/j.drugpo.2006.12.017

Davis, Mike (1992). City of quartz: Excavating the future in Los Angeles. New York: Vintage.

De Certeau, Michel (1994/1999). La invención de lo cotidiano. Habitar, cocinar. México, D.F.: Universidad Iberoamericana.

Delgado, Manuel (2011). El espacio público como ideología. Madrid: Catarata.

Delgado, Manuel (2016). Ciudadanismo. La reforma ética y estética del capitalismo. Madrid: Libros de la catarata.

Devine-Wright, Patrick \& Lyons, Evanthia (1997). Remembering pasts and representing places: The construction of national identities in Ireland. Fournal of Environmental Psychology, 17(1), 33-45. https://doi.org/10.1006/jevp.1996.0037

Di Masso, Andrés (2012). Grounding citizenship: Toward a political psychology of public space. Political Psychology, 33(1), 23-43. https://doi.org/10.1111/j.14679221.2011.00866.x

Di Masso, Andrés (2015). Micropolitics of public space: On the contested limits of citizenship as a locational practice. Journal of Social and Political Psychology, 3(2), 63-83. https://doi.org/10.5964/jspp.v3i2.322

Di Masso, Andrés \& Dixon, John (2015). More than words: Place, discourse and the struggle over public space in Barcelona. Qualitative Research in Psyhology, 12(1), 45-60. https://doi.org/10.1080/14780887.2014.958387

Dixon, John \& Durrheim, Kevin (2000). Displacing place-identity: A discursive approach to locating self and other. British Journal of Social Psychology, 39(1), 27-44. https://doi.org/10.1348/014466600164318

Dixon, John; Levine, Mark \& McAuley, Rob (2006). Locating impropriety: Street drinking, moral order, and the ideological dilemma of public space. Political Psychology, 27(2), 187-206. https://doi.org/10.1111/j.1467-9221.2006.00002.x

Eagleton, Terry (1991). Ideology: An introduction. London: Verso.

Farías, Ignacio \& Bender, Thomas (Eds.) (2010). Urban assemblages. How Actor-Network Theory Changes Urban Studies. Oxfordshire: Routledge.

Fischer, Claude (1981). The public and private worlds of city life. American Sociological Review, 46(3), 306-316. https://doi.org/10.2307/2095062

Francis, Mark (1989). Control as a dimension of public-space quality. En Irwin Altman \& Ervin Zube (Eds.), Public places and spaces (pp. 147-172). New York: Plenum Press.

Franck, Karen \& Stevens, Quentin (2006). Loose spaces. Possibility and diversity in urban life. New York: Routledge. 
Fraser, Nancy (1990). Rethinking the public sphere: A contribution to the critique of actually existing democracy. Social Text, 25/26, 56-80. https://doi.org/10.2307/466240

Garcia-Ramon, Maria Dolors; Ortiz, Anna \& Prats, Maria (2004). Urban planning, gender and the use of public space in a peripheral neighbourhood of Barcelona. Cities, 21(3), 215-223. https://doi.org/10.1016/j.cities.2004.03.006

Gehl, Jan (2001). Life between buildings. Copenhagen: The Danish Architectural Press.

Groth, Jacqueline \& Corijn, Eric (2005). Reclaiming urbanity: Indeterminate spaces, informal actors and urban agenda setting. Urban Studies, 42(3), 503-526. https://doi.org/10.1080/00420980500035436

Habermas, Jürgen (1989). The public sphere. En Steven Seidman (Ed.), fürgen Habermas on society and politics. A reader (pp. 231-236). Boston: Beacon Press.

Halsey, Mark \& Young, Alison (2006). 'Our desires are ungovernable'. Writing graffiti in urban space. Theoretical Criminology, 10(3), 275-306. https://doi.org/10.1177/1362480606065908

Harvey, David (1996). Justice, nature, and the geography of difference. Oxford: Blackwell.

Holston, James (1998). Spaces of insurgent citizenship. En Leonie Sandercock (Ed.), Making the invisible visible (pp. 37-55). Berkeley (Ca.): University of California Press.

Hou, Jeffrey (Ed.) (2010). Insurgent public space. Guerilla urbanism and the remaking of contemporary cities. New York: Routledge.

Jackson, Peter (1998). Domesticating the street. The contested spces of the High Street and the mall. En Nicholas Fyfe (Ed.), Images of the street. Planning, identity and control in public space (pp. 176-191). London: Routledge.

Jacobs, Jane (1961). The death and life of great American cities. New York: Random House.

Jeong, Sunny \& Almeida, Carla (2004). Cultural politics and contested place identity. Annals of Tourism Research, 31(3), 640-656. https://doi.org/10.1016/j.annals.2004.01.004

Kohn, Margaret (2004). Brave new neighborhoods. The privatization of public space. New York: Routledge.

Lefebvre, Henri (1968). El derecho a la ciudad. Barcelona: Península.

Lofland, Lyn (1998). The public realm: Exploring the city's quintessential social territory. New Jersey: Aldine Transaction.

Loukaki, Argyro (1997). Whose genius loci? Contrasting interpretations of the "sacred rock of the Athenian acropolis". Annals of the Association of American Geographers, 87(2), 306-329. https://doi.org/10.1111/0004-5608.872055

Low, Setha \& Smith, Neil (2006). The politics of public space. New York: Routledge.

Lynch, Kevin (1981). A theory of good city form. Cambridge MA: MIT Press.

Massey, Doreen (1994). Space, place and gender. Cambridge: Polity Press.

Massumi, Brian (2002). Parables for the virtual. Movement, affect, sensation. Durham \& London: Duke University Press. 
Milgram, Stanley (1970). The experience of living in cities. Science, 167(3924), 14611468. https://doi.org/10.1126/science.167.3924.1461

Mitchell, Don (1995). The end of public space? People's Park, definitions of the public, and democracy. Annals of the Association of American Geographers, 85(1), 108133. Recuperado de: http://links.jstor.org/sici?sici=00045608\%28199503\%2985\%3A1\%3C108\%3ATEOPSP\%3E2.0.CO\%3B2-M

Mitchell, Don (2003). The right to the city. Social justice and the fight for public space. New York: Guilford Press.

Nagar, Richa (2000). I'd rather be rude than ruled: Gender, place and communal politics among South Asian communities in Dar Es Salaam. Women's Studies International Forum, 23(5), 571-585. https://doi.org/10.1016/s02775395(00)00128-x

Neal, Zachary P. (2010). Locating public space. En Anthony M. Orum \& Zachary P. Neal (Eds.), Common ground? Readings and reflections on public space (pp. 110). New York: Routledge.

Newman, Oscar (1972). Defensible space: Crime prevention through urban design. New York: McMillan.

Oelofse, Catherine \& Dodson, Belinda (1997). Community, place and transformation: A perceptual analysis of residents' responses to an informal settlement in Hout Bay, South Africa. Geoforum, 28(1), 91-101. https://doi.org/10.1016/s0016$\underline{7185(97) 85529-7}$

Ortiz, Anna (2006). Uso de los espacios públicos y construcción del sentido de pertenencia de sus habitantes en Barcelona. En Alicia Lindón, Miguel Ángel Aguilar \& Daniel Hiernaux (Eds.), Lugares e imaginarios en la metrópolis (pp. 67-83). Barcelona: Anthropos.

Painter, Joe \& Philo, Chris. (1995). Spaces of citizenship: an introduction. Political Geography, 14(2), 117-120. https://doi.org/10.1016/0962-6298(95)91659-r

Pasagoullari, Nil \& Doratli, Naciye (2004). Measuring accessibility and utilization of public spaces in Famagusta. Cities, 21(3), 225-232.

https://doi.org/10.1016/j.cities.2004.03.003

Philp, Jannette \& Mercer, David (2002). Politicised pagodas and veiled resistance: Contested urban space in Burma. Urban Studies, 39(9), 1587-1610. https://doi.org/10.1080/00420980220151673

Popke, Jeffrey \& Ballard, Richard (2004). Dislocating modernity: Identity, space and representations of street trade in Durban, South Africa. Geoforum, 35(1), 99110. https://doi.org/10.1016/s0016-7185(03)00002-2

Rendueles, César (2013). Sociofobia. El cambio político en la era de la utopía digital. Madrid: Capitán Swing.

Rivlin, Leanne (1994). Public spaces and public life in urban areas. En Susan Neary, Martin Symes \& Frank Brown (Eds.), The urban experience: A peopleenvironment perspective (pp. 289-296). London: Chapman \& Hall.

Sennett, Richard (1974). El declive del hombre público. Barcelona: Península.

Sennett, Richard (2006). The culture of the new capitalism. Yale: Yale University Press. 
Simmel, Georg (1950). The stranger. En Kurt H. Wolff (Ed.), The sociology of Georg Simmel (pp. 402-408). New York: The Free Press.

Smith, Neil (2005). El redimensionamiento de las ciudades: la globalización y el urbanismo neoliberal. En David Harvey \& Neil Smith (Eds.), Capital financiero, propiedad inmobiliaria y cultura (pp. 59-75). Barcelona: MACBA i $\mathrm{UAB}$.

Smith, Neil \& Low, Setha (2006). Introduction: The imperative of public space. En Setha Low \& Neil Smith (Eds.), The politics of public space (pp. 1-16). New York: Routledge.

Snow, David \& Mulcahy, Maurice (2001). Space, politics, and the survival strategies of the homeless. American Behavioral Scientist, 45(1), 149-169. https://doi.org/10.1177/00027640121956962

Soja, Edward (1989). Postmodern geographies. The reassertion of space in critical social theory. London: Verso.

Sorkin, Michael (Ed.) (1992), Variations on a theme park. The new American city and the end of public space. Hill and Wang: New York.

Staeheli, Lynn \& Mitchell, Don (2008). The people's property? Power, politics and the public. New York: Routledge.

Staeheli, Lynn \& Thompson, Albert (1997). Citizenship, community, and struggles for public space. Professional Geographer, 49(1), 28-38.

https://doi.org/10.1111/0033-0124.00053

Stangl, Paul (2006). Restoring Berlin's Unter den Linden: Ideology, world view, place and space. Fournal of Historical Geography, 32(2), 352-376. https://doi.org/10.1016/j.jhg.2005.08.003

Stone, Gregory (1954). City shoppers and urban identification: Observations on the social psychology of city life. Americal fournal of Sociology, 60(1), 36-45. https://doi.org/10.1086/221483

Urzúa, Verónica (2012). El espacio público y el derecho a excluir. Athenea Digital, 12(1), 159-168. https://doi.org/10.5565/rev/athenead/v12n1.919

Walzer, Michael (1986, fall). Pleasures and costs of urbanity. Dissent Magazine. Recuperado de: https://www.dissentmagazine.org/article/pleasures-costs-ofurbanity

Ward Thompson, Catherine (2002). Urban open space in the 21st century. Landscape and Urban Planning, 60(2), 59-72. https://doi.org/10.1016/s0169-2046(02)00059$\underline{2}$

Whyte, William H. (1980). The social life of small urban spaces. New York: Project for Public Spaces.

Wu, Junjie \& Plantinga, Andrew (2003). The influence of public open space on urban spatial structure. Fournal of Environmental Economics and Management, 46(2), 288-309. https://doi.org/10.1016/s0095-0696(03)00023-8

Žižek, Slavoj (1994). Ideología: Un mapa de la cuestión. Buenos Aires: Paidós.

Zukin, Sharon (1995). The culture of cites. Malden Massachussets: Blackwell. 


\section{c) (7)}

Este texto está protegido por una licencia Creative Commons 4.0

Usted es libre para Compartir — copiar y redistribuir el material en cualquier medio o formato- y Adaptar el documento -remezclar, transformar y crear a partir del material- para cualquier propósito, incluso comercialmente, siempre que cumpla la condición de:

Atribución: Usted debe reconocer el crédito de una obra de manera adecuada, proporcionar un enlace a la licencia, e indicar si se han realizado cambios . Puede hacerlo en cualquier forma razonable, pero no de forma tal que sugiera que tiene el apoyo del licenciante o lo recibe por el uso que hace.

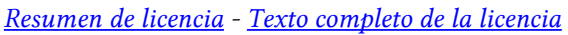

